\title{
Validation of three different scientific ozone products retrieved from IASI spectra using ozonesondes
}

\author{
G. Dufour $^{1}$, M. Eremenko ${ }^{1}$, A. Griesfeller ${ }^{1, *}$, B. Barret ${ }^{2,3}$, E. LeFlochmoën ${ }^{2,3}$, C. Clerbaux ${ }^{4,5}$, J. Hadji-Lazaro ${ }^{4}$, \\ P.-F. Coheur ${ }^{5}$, and D. Hurtmans ${ }^{5}$ \\ ${ }^{1}$ Laboratoire Inter-universitaire des Systèmes Atmosphériques (LISA), UMR7583, Universités Paris Est Créteil et Paris \\ Diderot, CNRS/INSU, Créteil, France \\ ${ }^{2}$ Laboratoire d'Aérologie/OMP, Université de Toulouse, Toulouse, France \\ ${ }^{3}$ CNRS/INSU, UMR5560, 14 Avenue E. Belin, 31400 Toulouse, France \\ ${ }^{4}$ UPMC Univ. Paris 6, Université Versailles St.-Quentin, CNRS/INSU, LATMOS-IPSL, Paris, France \\ ${ }^{5}$ Spectroscopie de l'Atmosphère, Chimie Quantique et Photophysique, Université Libre de Bruxelles (ULB), \\ Brussels, Belgium \\ *now at: Norsk Institutt for Luftforskning, NILU, Kjeller, Norway
}

Correspondence to: G. Dufour (dufour@lisa.u-pec.fr)

Received: 1 July 2011 - Published in Atmos. Meas. Tech. Discuss.: 23 August 2011

Revised: 9 March 2012 - Accepted: 16 March 2012 - Published: 27 March 2012

\begin{abstract}
Three scientific ozone products from the Infrared Atmospheric Sounding Interferometer (IASI) aboard MetOp-A, retrieved in three different research teams (LA, LATMOS/ULB, LISA) with different retrieval schemes, are characterized and validated using ozonesondes measurements. The characteristics of the products are analyzed in terms of retrieval sensitivity, systematic and random errors, and ability to retrieve the natural variability of ozone and focus on different partial columns from the lower troposphere up to $30 \mathrm{~km}$. The validation covers the midlatitudes and the tropics and the period from January to December 2008. The products present degrees of freedom (DOF) in the troposphere between 1 and 1.2 on average in the midlatitudes and between 1 and 1.4 in the tropics. The DOF are distributed differently on the vertical depending on the profiles and the season: summer leading to a better sensitivity to the lower troposphere, as expected. The error estimates range between 10 and $20 \%$ from the lower tropospheric partial columns (0-6 $\mathrm{km}$ and $0-8 \mathrm{~km}$ for the midlatitudes and the tropics respectively) to the UTLS partial columns (8-16 km and 11$20 \mathrm{~km}$ for the midlatitudes and the tropics respectively) for all the products and are about $5 \%$ in the stratosphere (16$30 \mathrm{~km}$ ) and for the column up to $30 \mathrm{~km}$. The main feature that arises from the comparison with the ozonesondes is a systematic overestimation of ozone in the UTLS (between 10 and $25 \%$ ) by the three products in the midlatitudes and the
\end{abstract}

tropics, attributed to the moderate vertical resolution of IASI and possibly to spectroscopic inconsistencies. The ability of the products to reproduce natural variability of tropospheric ozone is fairly good and depends on the considered season and region.

\section{Introduction}

Ozone plays a central role in the photochemical equilibrium of the atmosphere. In the stratosphere, the ozone layer absorbs harmful ultraviolet solar radiation allowing life on Earth. In the troposphere, ozone is a key component for the atmospheric radiative forcing, for the oxidative capacity of the atmosphere and for air quality with a significant impact on human health and vegetation (Seinfeld and Pandis, 1997). Due to its role in different compartments of the atmosphere and at different spatial scale, global or large scale monitoring of ozone is essential. Only satellitebased instruments can provide observations of ozone at such scales. However, measurement of ozone in the troposphere is difficult because the contribution to the measured signal from the stratosphere is typically large. The first satellite measurements of tropospheric ozone were obtained using ultraviolet-visible (UV-vis) sounders (e.g. Fishmann et al., 2003; Liu et al., 2005) but UV-vis instruments remain 
weakly sensitive to the tropospheric ozone content by nature. Thermal infrared nadir sounders offer maximum of sensitivity in the troposphere with a vertical resolution of about 6-7 km (Coheur et al., 2005; Worden et al., 2007). Their recent development allows accurate measurements of tropospheric ozone. The first demonstration of probing global tropospheric ozone has been made from the Interferometric Monitor Greenhouse gases (IMG) instrument (Turquety et al., 2002; Coheur et al., 2005). The capabilities of thermal infrared sounders monitoring tropospheric ozone have been further demonstrated and applied by the Tropospheric Emission Spectrometer (TES) instrument aboard EOS-AURA and the Infrared Atmospheric Sounding Interferometer (IASI) instrument aboard MetOp-A for studying atmospheric composition and transport, climate and air quality (e.g. Worden et al., 2008; Jones et al., 2008; Eremenko et al., 2008; Boynard et al., 2009; Dufour et al., 2010). Recently, the ability to separate the ozone content of the lower and the upper troposphere in summer conditions made a step towards the use of infrared sounders to help monitoring air quality in largely polluted regions (Dufour et al., 2010).

Ozone concentrations from satellite measurements are typically inferred from measured radiances using a nonlinear least squares approach that involves minimizing a cost function depending on the radiance and a forward model of the geophysical parameters (including ozone concentrations) that affect the radiance. If a profile of ozone is estimated from the radiance then the problem is ill-posed and the cost function needs to be augmented by an additional term that, either describes the a priori statistics of the atmosphere or corresponds to a mathematical constraint. It is then necessary to intensively validate the observations in order to well characterize the performances of the retrieved product (ozone profiles or partial columns in our case) in terms of systematic and random errors, retrieval sensitivity, etc. Comparisons with independent observations, typically ozonesondes, allow one to determine the systematic errors (given by the bias), the random error (given by the root mean square of the difference) and also allow one to determine the ability of the retrieved product to reproduce variability of ozone. However, validation is often difficult because the number of independent measurements remains small and does not give a complete view of the range of the situations that the satellite can encounter. The available measurements often correspond to background conditions for ozone. Moreover, the temporal and spatial representativeness of the measurement is not always consistent with satellite observations. Specific methods can be applied to make the observations consistent for example in terms of vertical resolution, when possible. For the validation of satellite ozone products, ozonesondes are commonly used as reference measurements (e.g. Worden et al., 2007; Nassar et al., 2008; Keim et al., 2009; Boxe et al., 2010). The large networks of stations available (WOUDC, SHADOZ, etc) provide a good sampling for representing background and climatological variations of ozone.
A first validation exercise for different ozone products of IASI under development was presented by Keim et al. (2009). In this paper, we present a new validation exercise for three ozone products retrieved in three different research teams: Laboratoire D'Aérologie (LA), Laboratoire Atmosphères, Milieux, Observations Spatiales and Université Libre de Bruxelles (LATMOS/ULB), and Laboratoire Interuniversitaire des Systèmes Atmosphériques (LISA). These three products are based on radiative transfer models and retrieval strategies that were already validated (Keim et al., 2009; Barret et al., 2011; Boynard et al., 2009) and used to conduct analyses on the atmospheric composition and the transport (e.g. troposphere/stratosphere exchanges, air quality monitoring, etc.) (Eremenko et al., 2008; Dufour et al., 2010; Barret, et al., 2011; Scannell et al., 2012). It is worth pointing out, however, that they do not have the same priorities (e.g. near-real-time constraints, provision of local or global datasets) and are therefore not optimized similarly. After a brief description of the IASI instrument in Sect. 2, the three products are described and characterized in terms of retrieval sensitivity in Sect. 3. Section 4 presents the ozonesondes measurements used in this study and describes the method used for the comparison. Sections 5 and 6 present the results of the comparison between the three products and the ozonesonde measurements for the midlatitudes and the tropics respectively.

\section{The IASI instrument}

IASI (Clerbaux et al., 2009) is a nadir viewing spectrometer onboard the MetOp-A satellite and was designed for operational meteorology as a primary objective and for monitoring climate and atmospheric chemistry as a secondary objective. The MetOp-A satellite launched in October 2006 flies in a polar sun-synchronous orbit (about $800 \mathrm{~km}$ altitude) and crosses the equatorial plane at two fixed 09:30 a.m. LST (local solar times) (descending mode) and 09:30 p.m. LST (ascending mode). The IASI instrument is a Fouriertransform spectrometer with a 2-cm maximal optical path difference covering the $645-2760 \mathrm{~cm}^{-1}$ spectral range. The apodized spectral resolution is $0.5 \mathrm{~cm}^{-1}$ (Full-Width at HalfMaximum). The radiometric accuracy in noise-equivalent radiance temperature at $280 \mathrm{~K}$ is better than $0.20 \mathrm{~K}$ in the ozone spectral region near $9.6 \mu \mathrm{m}$. IASI measures the thermal infrared radiation (TIR) emitted by the Earth's surface and the atmosphere. The instrument scans the surface perpendicular to the satellite's flight track with 15 individual views on each side of the track. The distance between two successive overpasses is $25^{\circ}$ in longitude (i.e. $2800 \mathrm{~km}$ ) at the equator. For latitudes higher than $45^{\circ}$, the footprints of two successive overpasses overlap. At the nadir point, the view size is $50 \times 50 \mathrm{~km}^{2}$. The view is composed of 4 individual ground pixels of $12 \mathrm{~km}$ diameter each. The maximum scan angle of $48.3^{\circ}$ from the nadir corresponds to coverage for one swath 
of about $2200 \mathrm{~km}$ in the direction perpendicular to the satellite's track.

The primary objective of the IASI instrument is to deliver meteorological products (surface temperature, temperature and humidity profiles, and cloud information). The large spectral cover and the relatively high spectral resolution of the instrument allow deriving distributions of several trace gases (Clerbaux et al., 2009; Clarisse et al., 2011), including $\mathrm{O}_{3}$ and $\mathrm{CO}$ (e.g. Eremenko et al., 2008; Turquety et al., 2009).

\section{The IASI ozone products: description and characteristics}

In this section, the three products considered in the present study are described and their characteristics in terms of retrieval sensitivity (especially in the troposphere) and in terms of error estimates are discussed.

We recall here some generalities on the retrieval and the parameters used to characterize the retrieval performances developed in Rodgers (2000). The relationship between the atmospheric state $\boldsymbol{x}$ (the ozone vertical profile in our case), the measured radiances given by the measurement vector $\boldsymbol{y}$, the measurement noise vector $\boldsymbol{\varepsilon}$ and the radiative transfer model $F$ is:

$\boldsymbol{y}=F(\boldsymbol{x})+\boldsymbol{\varepsilon}$.

To retrieve the atmospheric state $\boldsymbol{x}$, Eq. (1) has to be inverted. The inverse problem being formally overdetermined, it is necessary to apply a constrained least-squares fit method to retrieve $\boldsymbol{x}$ properly. The cost function to minimize is given in Eq. (2).

$[\boldsymbol{y}-F(x)]^{T} \mathbf{S}_{\varepsilon}^{-1}[\boldsymbol{y}-F(\boldsymbol{x})]+\left[\boldsymbol{x}-\boldsymbol{x}_{\mathrm{a}}\right]^{T} \mathbf{R}\left[\boldsymbol{x}-\boldsymbol{x}_{\mathrm{a}}\right]$

where $\mathbf{S}_{\varepsilon}$ is the error covariance matrix of the measurement, $\boldsymbol{x}_{\mathrm{a}}$ is the a priori state vector and $\mathbf{R}$ is a regularization matrix. This matrix can be defined in the formalism of the optimal estimation method (usually noted $\mathbf{S}_{\mathrm{a}}^{-1}$ ) or in the formalism of a mathematical constraint of Tikhonov-Philipps type (Steck, 2002). In Rodgers formalism, the averaging kernels (Eq. 3) are used to characterize the sensitivity of the retrieved state to the true state. The vertical sensitivity of the retrievals is usually represented by the degrees of freedom for the signal (DOF) that give the number of independent pieces of information in the retrieved profile (Eq. 4).

$\mathbf{A}=\left(\mathbf{K}^{T} \mathbf{S}_{\varepsilon}^{-1} \mathbf{K}+\mathbf{R}\right)^{-1} \mathbf{K}^{T} \mathbf{S}_{\varepsilon}^{-1} \mathbf{K}=\mathbf{G}_{y} \mathbf{K}$

$\mathbf{K}$ represents the Jacobian of the radiative transfer model $F$ against the atmospheric state and $\mathbf{G}_{y}$ the gain matrix.

$\mathrm{DOF}=\operatorname{tr}(\mathbf{A})$

For the error analysis, the components considered in this study are the measurement noise error and the smoothing error defined by their covariance matrices given respectively by Eqs. (5) and (6). Several studies have shown that the smoothing error largely dominates the error, followed by the measurement noise errors (Coheur et al., 2005; Boynard et al., 2009).

$\mathbf{S}_{\mathrm{m}}=\mathbf{G}_{y} \mathbf{S}_{\varepsilon} \mathbf{G}_{y}^{T}$

$\mathbf{S}_{\mathrm{s}}=(\mathbf{A}-\mathbf{I}) \mathbf{S}_{\mathrm{a}}(\mathbf{A}-\mathbf{I})^{T}$

Note that the degrees of freedom accessible from the IASI radiances remain limited for ozone retrieved profiles, between 3 and 4 over the entire atmosphere (Clerbaux et al., 2009; Keim et al., 2009). In the following, we consider preferably ozone partial columns with DOF close to one (except for the lower troposphere). The partial columns considered in the following are: the lower tropospheric (LT) column defined as the column from 0 to $6 \mathrm{~km}$ for the midlatitudes and from 0 to $8 \mathrm{~km}$ for the tropics; the tropospheric (TROPO) column defined as the column from 0 to $11 \mathrm{~km}$ for the midlatitudes and from 0 to $16 \mathrm{~km}$ for the tropics; the upper tropospheric lower stratospheric (UTLS) column integrated from 8 to $16 \mathrm{~km}$ in the midlatitudes and from 11 to $20 \mathrm{~km}$ in the tropics; the stratospheric (STRATO) column from 16 to $30 \mathrm{~km}$ and the column integrated over the measurement range of the ozonesondes i.e. from 0 to $30 \mathrm{~km}$ (UPTO30). The upper limit of $30 \mathrm{~km}$ is driven by the upper altitude of the ozonesonde.

\subsection{LA product}

The $\mathrm{O}_{3}$ profiles from LA are produced with the Software for a Fast Retrieval of IASI Data (SOFRID) described in Barret et al. (2011). This retrieval software is based on the RTTOV (Radiative Transfer for TOVS) fast radiative transfer model (Saunders et al., 1999; Matricardi et al., 2004) developed jointly by the UK Met Office (UKMO), the European Center for Medium Range Weather Forecasts (ECMWF) and Meteo France. RTTOV uses a parameterization of atmospheric optical depths that makes the model accurate and fast enough to be used for the operational assimilation of satellite radiance data in Numerical Weather Prediction (NWP). The overall accuracy of RTTOV is discussed in detail by Matricardi et al. (2009). The RTTOV regression coefficients are based on LBL computations performed using the HITRAN2004 spectroscopic database (Rothman et al., 2005) and the land surface emissivity is computed with the RTTOV UW-IRemis module (Borbas et al., 2010).

The SOFRID retrievals are performed with the UKMO 1D-Var algorithm (Pavelin et al., 2008) based on the Optimal Estimation Method (OEM) (Rodgers, 2000). The $\mathrm{O}_{3}$ a priori state, mean profile and covariance matrix (Barret et al., 2011) is based on an ensemble of in-situ $\mathrm{O}_{3}$ profiles measured in 2008 by radiosounding and by the MOZAIC (Measurements of OZone, water vapour, carbon monoxide and nitrogen oxides by in-service AIrbus airCraft, Thouret et al., 1998) instrumented aircraft. The in-situ profiles are 
completed above their uppermost altitude by coincident $\mathrm{O}_{3}$ profiles from Aura/MLS assimilated data. Therefore, the SOFRID covariance matrix, based on an ensemble of several thousands of individual measured profiles is characterised by a high variability both in the LT (70\%) and in the UTLS (80$90 \%$ ).

The temperature and water vapour atmospheric profiles required for the radiative transfer computations are EUMETSAT operational IASI level 2 products. IASI Elementary Field Of View (EFOV) corresponds to 4 pixels for which the measurements are acquired simultaneously. Until March 2010, IASI NRT L2 products from EUMETSAT disseminated through the Eumetcast system and used in this study were only provided for pixels 1 and 3 of the EFOV. Therefore we have used the same temperature and water vapour profiles for pixel 2 (resp. 4) than for pixel 1 (resp. 3).These atmospheric parameters are held constant during the retrieval. The $\mathrm{O}_{3}$ profiles are retrieved from the $1025-1075 \mathrm{~cm}^{-1}$ spectral window such as in Boynard et al. (2009). This reduction of the $\mathrm{O}_{3}$ retrieval window relative to Barret et al. (2011) allowed us to avoid interferences with $\mathrm{H}_{2} \mathrm{O}$ absorptions and to optimize the computation time without significantly reducing the information content as mentioned in Boynard et al. (2009). In the present study, the IASI measurement noise covariance matrix set up in the 1D-Var scheme is diagonal with a single noise value for the $\mathrm{O}_{3}$ spectral window. The IASI radiometric noise has been estimated to be of the order of $20 \mathrm{nW} /\left(\mathrm{cm}^{2} \mathrm{~cm}^{-1} \mathrm{sr}\right)$ around $900 \mathrm{~cm}^{-1}$ in Clerbaux et al. (2009). Because the radiative transfer simulations are impacted by sources of error other than the radiometric noise (such as uncertainties on the temperature and water vapor profiles, the surface emissivity and, the spectroscopic parameters) the measurement noise level used for the retrieval has to be taken conservatively. Based on sensitivity tests, we use a noise level of $60 \mathrm{nW} /\left(\mathrm{cm}^{2} \mathrm{~cm}^{-1} \mathrm{sr}\right)$ for the midlatitudes and of $80 \mathrm{nW} /\left(\mathrm{cm}^{2} \mathrm{~cm}^{-1} \mathrm{sr}\right)$ for the tropics. These values are close to 80 (resp. 70) $\mathrm{nW} /\left(\mathrm{cm}^{2} \mathrm{~cm}^{-1} \mathrm{sr}\right.$ ), values used by Barret et al. (2011) (resp. Boynard et al., 2009) for IASI $\mathrm{O}_{3}$ retrievals. The choice of conservative noise values for the retrievals is partly compensated by the use of an a priori covariance matrix with high variabilities.

The cloud filtering was performed according to Clerbaux et al. (2009), based on the AVHRR-derived fractional cloud cover from the IASI EUMETSAT L2 products. All pixels corresponding to a fractional cloud cover between 0 and $25 \%$ are processed and treated as cloud free pixels. For pixels with unavailable cloud fraction, we use a cloud filter based upon differences between surface temperatures retrieved from IASI measured radiances at 11 and 12 microns and from the ECMWF analyses (Barret et al., 2011). The SOFRID, based on an operational radiative transfer algorithm (RTTOV), allows Near Real Time global processing of IASI ozone.

\subsection{LATMOS/ULB product}

Ozone products are retrieved in near-real-time and globally twice daily from the IASI radiance spectra at LATMOS/ULB using the FORLI-O3 (Fast Optimal Retrievals on Layers for IASI) software (Hurtmans et al., 2012). Version 20100815 was used for this study. The software generates ozone profiles on a $401-\mathrm{km}$ thick layers between the surface and $40 \mathrm{~km}$, along with the associated averaging kernels and error matrices, on the global scale. It was designed to allow the fast delivery of a global near real time product from the more than 1.3 million IASI observations per day which are distributed via the Eumetcast dissimination system. Ozone retrievals are performed in the $1025-1075 \mathrm{~cm}^{-1}$ spectral range, in order to minimize the computation time and avoid interferences with water vapour lines. This reduced window was shown to contain all the available information for retrieving ozone profiles from thermal radiance (Boynard et al., 2009).

The minimizing scheme is based on the Optimal Estimation Method (OEM) as described by Rodgers (2000). To allow near-real-time processing, FORLI uses pre-calculated look up tables of absorbance cross sections at various pressures and temperatures in a larger spectral region around the ozone band, from 960 to $1075 \mathrm{~cm}^{-1}$. These tables are pre-computed on a logarithmic grid for pressure $\left(4.5 \times 10^{-5}-1 \mathrm{~atm}\right)$ on a linear grid for temperature $(162.8 \mathrm{~K}-322.6 \mathrm{~K})$, and, for water vapour, on a linear grid in relative humidity, using the HITRAN databases (Rothman et al., 2005). The operational Level 2 temperature and water vapour profiles distributed by Eumetcast (Schluessel et al., 2005) are used as inputs of the code as well as surface emissivity. These are taken from the monthly climatologies established by Zhou et al. (2011) wherever available, or the from the MODIS/TERRA climatology (Wan, 2008).

The a priori profile and associated covariance matrix were constructed using the Logan/Labow/McPeters global climatological database (McPeters et al., 2007). This ozone climatology is altitude dependent and consists of monthly averaged ozone profiles for $10^{\circ}$ latitude zones from 0 to $60 \mathrm{~km}$. This climatology is a combination of data from the Stratospheric Aerosol and Gas Experiment II (SAGE II; 1988 2001), the Microwave Limb Sounder (MLS; 1991-1999) and data from balloon sondes (1988-2002).

The measurement covariance matrix is assumed to be diagonal with an average noise value in the retrieval range of $2 \times 10^{-8} \mathrm{~W} /\left(\mathrm{cm}^{2} \mathrm{~cm}^{-1} \mathrm{sr}\right)$. The retrievals settings implemented in FORLI-O ${ }_{3}$ allow the provision of ozone distributions at all latitudes and seasons using the same a priori and covariance matrix information. Validation with groundbased Brewer instruments is provided in Anton et al. (2011).

Retrievals are performed only for scenes with cloud contamination of less than $13 \%$, using the Eumetsat operational level 2 cloud parameters (Clerbaux et al., 2009). Quality flags are available with the LATMOS/ULB products in order to characterize each retrieval and to allow a proper use of 
Table 1. Summary of the retrieval properties of the three products.

\begin{tabular}{|c|c|c|c|}
\hline & LA & LATMOS/ULB & LISA \\
\hline \multicolumn{4}{|c|}{ Radiative transfer model and retrieval approach } \\
\hline RTM & SOFRID/RTTOV & FORLI & KOPRA-KOPRAFIT \\
\hline Type & Parametrization of AOD & Lookup tables & Line-by-line \\
\hline Retrieval method ${ }^{\mathrm{a}}$ & OEM & OEM & Altitude dependent TP \\
\hline A priori & Radiosoundings + MOZAIC + MLS & McPeters et al. (2007) & McPeters et al. (2007) \\
\hline Error matrix ${ }^{b}$ & Midlatitudes: 60, tropics: 80 & 20 & 20 \\
\hline Spectral range & $1025-1075 \mathrm{~cm}^{-1}$ & $1025-1075 \mathrm{~cm}^{-1}$ & 7 in $\left[975-1100 \mathrm{~cm}^{-1}\right]$ \\
\hline Spectroscopic database & HITRAN 2004 & HITRAN 2004 & HITRAN 2004 \\
\hline \multicolumn{4}{|c|}{ Auxiliary information } \\
\hline Temperature & Operational L2 (4 pixels $\left.{ }^{\mathrm{c}}\right)$ & Operational L2 (2 pixels) & Retrieved \\
\hline Emissivity & MODIS U. Winconsin Global IR emissivity & IASI climatology $\mathrm{d}$ & Not included \\
\hline Cloud filter & L2 - AVHRR $(25 \%)+$ Tsurf at 11 and $12 \mu \mathrm{m}$ & L2 - AVHRR (13\%) & Tsurf + baseline analysis ${ }^{\mathrm{e}}$ \\
\hline
\end{tabular}

${ }^{\mathrm{a}}$ OEM: optimal estimation method; TP: Tikhonov-Philips; ${ }^{\mathrm{b}}$ diagonal matrices - units: $\mathrm{nW} /\left(\mathrm{cm}^{2} \mathrm{~cm}^{-1} \mathrm{sr}\right)$; ${ }^{\mathrm{c}}$ See the description of the LA product for details on the method used to overcome the distribution of half of the pixels; ${ }^{\mathrm{d}}$ Monthly climatology of emissivities retrieved at from IASI, at IASI spectral sampling (Zhou et al., 2011). When unavailable, the MODIS/TERRA climatology is used (Wan et al., 2008); ${ }^{\mathrm{e}}$ Combination of surface temperature threshold and baseline distortion analysis (Eremenko et al., 2008).

the data depending on the scientific application: for validation purpose, for ozone depletion or stratospheric intrusion studies, as well as for air quality assessment.

\subsection{LISA product}

The LISA retrievals are based on the radiative transfer model KOPRA (Karlsruhe Optimised and Precise Radiative transfer Algorithm, Stiller et al., 2000) and its inversion module KOPRAFIT, both adapted to the nadir-viewing geometry. A constrained least squares fit method using an analytical altitude-dependent regularization is used (Kulawik et al., 2006). The regularization method applied is detailed in Eremenko et al. (2008). To summarize, the regularization matrix is a combination of zero, first and second order Tikhonov constraints (Tikhonov, 1963) with altitude-dependent coefficients. The coefficients are optimized both to maximize the degrees of freedom (DOF) of the retrieval and to minimize the total error on the retrieved profile. The regularization matrix used in this study is the same than those used in Eremenko et al. (2008) for the midlatitudes and in Dufour et al. (2010) for the tropics. The a priori profiles used during the retrieval are compiled from the climatology of McPeters et al. (2007) and are different for the midlatitudes and the tropics. The midlatitude a priori profile is set to the climatological profile of the $30-60^{\circ} \mathrm{N}$ latitude band for summer and the tropical a priori profile is set to the climatological profile of the $10-30^{\circ} \mathrm{N}$ latitude band for one year. The a priori profile is independent of the season considered. It is worth noting that the main objective of the LISA product is to monitor tropospheric ozone for air quality assessments especially in the most affected regions of the midlatitudes. As most of the ozone pollution events occur during summer, the regularization for the midlatitudes was optimized for summer conditions.

The analysis of IASI data is performed in three steps. First, the effective surface temperature is retrieved from selected windows between 800 and $950 \mathrm{~cm}^{-1}$ considering a blackbody with an emissivity equal to unity. In the second step, the atmospheric temperature profile is retrieved from $\mathrm{CO}_{2}$ lines in the $15 \mu \mathrm{m}$ spectral region and using the ECMWF profiles as a priori. In the third step, the ozone profiles are retrieved from seven spectral windows in the $975-1100 \mathrm{~cm}^{-1}$ region that avoid strong water vapor lines. An offset is simultaneously fitted for each of the windows and should account for small deviations compared to emissivity equal to one. For larger deviations, either the retrieval crashes, or it is screened by the quality filters. The spectroscopic parameters are taken from HITRAN 2004 (Rothman et al., 2005). Note that before the retrieval, the IASI spectra are filtered for cloud contamination. The filter is based on threshold on the retrieved surface temperature and on the shape of the baseline of the spectra (Eremenko et al., 2008). A quality flag is also applied to the retrieved profiles to discard unphysical results (large negative values, large oscillations, etc.). We checked that the final set of pixels which have passed all the filters is consistent with cloud masks derived from the AVHRR instrument performing onboard MetOp-A.

\subsection{Summary of the characteristics of the different products}

Table 1 summarizes the main properties of the three retrieval set-ups. Note that satellite derived products are usually characterized in terms of the instrument vertical sensitivity and of the retrieval errors. These are, however, critically dependent 
Table 2. Ozonesonde stations used for the validation in the midlatitudes. The number of available measurements used in the validation is detailed as well as the number of selected pixels of IASI.

\begin{tabular}{lrlrr}
\hline Station name & \multicolumn{2}{c}{ Location } & $\begin{array}{r}\text { Nb of sonde } \\
\text { measurements }\end{array}$ & Nb of pixels $^{\mathrm{b}}$ \\
\hline Churchill (Canada) & $58.7^{\circ} \mathrm{N}$ & $94.1^{\circ} \mathrm{W}$ & 15 & 48 \\
Edmonton (Canada) & $53.5^{\circ} \mathrm{N}$ & $114.1^{\circ} \mathrm{W}$ & 44 & 143 \\
Goose Bay (Canada) & $53.3^{\circ} \mathrm{N}$ & $60.4^{\circ} \mathrm{W}$ & 10 & 31 \\
Legionowo (Poland) & $52.4^{\circ} \mathrm{N}$ & $21.0^{\circ} \mathrm{E}$ & 15 & 56 \\
Lindenberg (Germany) & $52.2^{\circ} \mathrm{N}$ & $14.1^{\circ} \mathrm{E}$ & 19 & 57 \\
Valentia (Ireland) & $51.9^{\circ} \mathrm{N}$ & $10.3^{\circ} \mathrm{W}$ & 17 & 48 \\
Bratts Lake (Canada) & $50.2^{\circ} \mathrm{N}$ & $104.7^{\circ} \mathrm{W}$ & 25 & 82 \\
Praha (Czech Republic) & $50.0^{\circ} \mathrm{N}$ & $14.4^{\circ} \mathrm{E}$ & 14 & 42 \\
Kelowna (Canada) & $49.9^{\circ} \mathrm{N}$ & $119.4^{\circ} \mathrm{W}$ & 10 & 13 \\
Hohenpeissenberg (Germany) & $47.8^{\circ} \mathrm{N}$ & $11.0^{\circ} \mathrm{E}$ & 28 & 79 \\
Payerne (Switzerland) & $46.5^{\circ} \mathrm{N}$ & $6.6^{\circ} \mathrm{E}$ & 43 & 126 \\
Trinidad Head (USA) & $40.8^{\circ} \mathrm{N}$ & $124.2^{\circ} \mathrm{W}$ & 24 & 53 \\
Madrid (Spain) & $40.5^{\circ} \mathrm{N}$ & $3.6^{\circ} \mathrm{W}$ & 16 & 45 \\
Boulder (USA) & $40.0^{\circ} \mathrm{N}$ & $105.3^{\circ} \mathrm{W}$ & 7 & 19 \\
Ankara (Turkey) & $40.0^{\circ} \mathrm{N}$ & $32.9^{\circ} \mathrm{E}$ & 9 & 22 \\
Wallops Island (USA) & $37.9^{\circ} \mathrm{N}$ & $75.5^{\circ} \mathrm{W}$ & 14 & 48 \\
Macquarie Island (Australia) & $54.5^{\circ} \mathrm{S}$ & $158.9^{\circ} \mathrm{E}$ & 3 & 11 \\
Ushuaia (Argentina) & $54.9^{\circ} \mathrm{S}$ & $68.3^{\circ} \mathrm{W}$ & 720 & 941 \\
\hline All stations & & & & 18 \\
\hline & & & &
\end{tabular}

a Number of days with sonde measurements considered in the validation exercise.

b Number of IASI pixels in coincidence with sonde measurements (see text for criteria) considered in the validation exercise.

on the constraint applied to the retrievals, and in particular to the a priori covariance matrix $\mathbf{S}_{\mathrm{a}}$ or regularization matrix and to the noise covariance matrix $\mathbf{S}_{\varepsilon}$. The latter are different in each retrieval software considered here (Table 1), and depend on the priorities put on the final product (e.g. the LISA retrievals in the midlatitues target more specifically tropospheric ozone for summer). The comparative analysis performed hereafter should therefore be considered mainly in the perspective to better understand the differences in the retrieved ozone columns described in Sect. 5.

The characterization of the three products is conducted over sets of pixels in coincidence with ozonesonde measurements defined for the validation exercise. Two sets of pixels have been defined: one for the midlatitudes and one for the tropics (Tables 2 and 3, respectively). The choice of the coincident pixels is detailed in Sect. 4. In this section, we use these sets of pixels to characterize the product in terms of retrieval sensitivity and estimation of errors on the products. The total degrees of freedom (integrated over the entire atmosphere) range on average between 2.8 (LA product) to 3.3 (LATMOS/ULB product) in the midlatitudes and from 2.8 (LA product) to 3.7 (LATMOS/ULB product) in the tropics (Table 4). The distribution of the degrees of freedom for the LT, TROPO and UTLS partial columns in the midlatitudes is shown in Fig. 1. The DOF in the UTLS is similar for the three products ( 0.9 on average). The LISA product, which
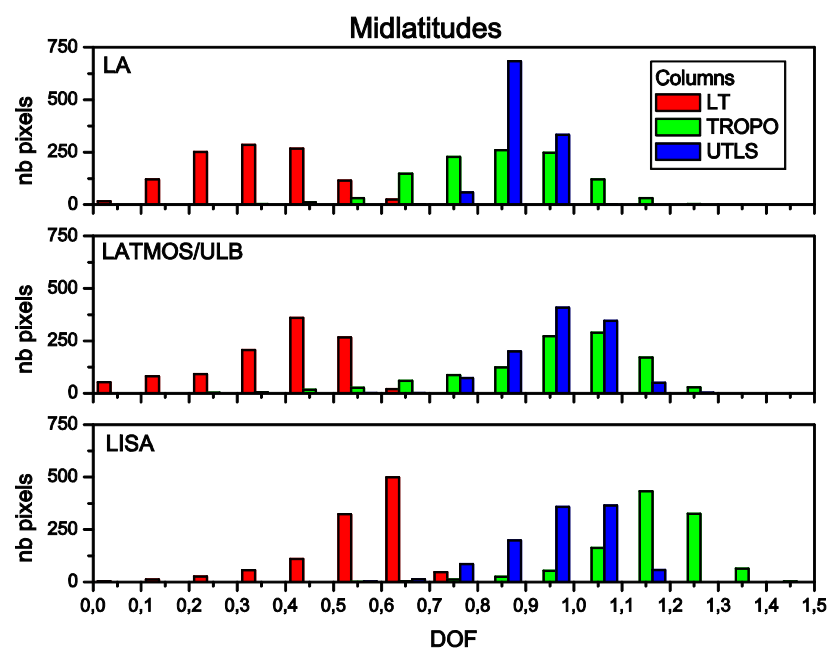

Fig. 1. Distribution of the degrees of freedom of the LT, TROPO and UTLS partial columns of ozone given over the set of pixels selected for the validation. The distribution for the LA, LATMOS/ULB and LISA products are presented in the top, middle and bottom panels, respectively. 
Table 3. Same as Table 2 but for the tropical ozonesonde stations.

\begin{tabular}{|c|c|c|c|c|}
\hline \multirow{2}{*}{$\begin{array}{l}\text { Station name } \\
\text { Naha (Japan) }\end{array}$} & \multicolumn{2}{|c|}{ Location } & \multirow{2}{*}{$\begin{array}{r}\mathrm{Nb} \text { of sonde } \\
\text { measurements }\end{array}$} & \multirow{2}{*}{$\begin{array}{r}\mathrm{Nb} \text { of pixels } \\
33\end{array}$} \\
\hline & $26.2^{\circ} \mathrm{N}$ & $127.7^{\circ} \mathrm{E}$ & & \\
\hline Hong Kong (China) & $22.3^{\circ} \mathrm{N}$ & $114.2^{\circ} \mathrm{E}$ & 8 & 26 \\
\hline Hilo (USA) & $19.4^{\circ} \mathrm{N}$ & $155.0^{\circ} \mathrm{W}$ & 13 & 34 \\
\hline Alajuela (Costa Rica) & $10.0^{\circ} \mathrm{N}$ & $84.2^{\circ} \mathrm{W}$ & 4 & 7 \\
\hline Paramaribo (Suriname) & $5.8^{\circ} \mathrm{N}$ & $55.2^{\circ} \mathrm{W}$ & 2 & 7 \\
\hline San Cristobal (Ecuador) & $0.9^{\circ} \mathrm{S}$ & $89.6^{\circ} \mathrm{W}$ & 6 & 15 \\
\hline Nairobi (Kenya) & $1.3^{\circ} \mathrm{S}$ & $36.8^{\circ} \mathrm{E}$ & 5 & 11 \\
\hline Maxaranguape (Brazil) & $5.5^{\circ} \mathrm{S}$ & $35.2^{\circ} \mathrm{W}$ & 7 & 29 \\
\hline Watukosek (Indonesia) & $7.5^{\circ} \mathrm{S}$ & $112.6^{\circ} \mathrm{E}$ & 1 & 1 \\
\hline Ascension (Saint Helena) & $8.0^{\circ} \mathrm{S}$ & $14.4^{\circ} \mathrm{W}$ & 1 & 5 \\
\hline Samoa (American Samoa) & $14.2^{\circ} \mathrm{S}$ & $170.6^{\circ} \mathrm{W}$ & 3 & 9 \\
\hline La Réunion (France) & $21.1^{\circ} \mathrm{S}$ & $55.5^{\circ} \mathrm{E}$ & 12 & 33 \\
\hline Irene (South Africa) & $25.9^{\circ} \mathrm{S}$ & $28.2^{\circ} \mathrm{E}$ & 1 & 5 \\
\hline All stations & & & 70 & 220 \\
\hline
\end{tabular}

is optimized for the retrieval of ozone in the lowest layers, shows slightly larger DOF in the LT and the TROPO partial columns compared to the LA and the LATMOS/ULB products. Actually, the mean DOF is 0.6 for the LT column and 1.2 for the TROPO column. For comparison the DOF of the LA and LATMOS/ULB products are 0.4 and 0.9 on average for the LT and TROPO columns, respectively. In compensation, the DOF of the LISA product is slightly smaller in the stratosphere compared to the other products (1.06 on average compared to 1.10 and 1.24). The absence of significant differences between LATMOS/ULB and LA relative to the DOF for TROPO, both in the midlatitudes and in the tropics, shows that the higher total DOF for the LATMOS/ULB product is mostly concerning the stratosphere. Table 4 reports also the seasonal variation between winter and summer of the sensitivity of the products from the lower troposphere to the UTLS. As expected, the DOF are larger in summer compared to winter due to thermal conditions more favorable for a higher sensitivity to the lower atmosphere. In the tropics, the LISA product shows larger DOF in the LT compared to the LA and LATMOS products but lower DOF in the UTLS (Table 4).

It is interesting to relate the DOF to the altitude of the maximum of the averaging kernels, which gives the altitude of the maximum of sensitivity of the product. To do this, we calculate the averaging kernels of the different partial columns (LT, TROPO and UTLS) and we search for the altitude of the maximum. The distribution of the altitude in the midlatitudes is given for the three columns in Fig. 2. The LISA product is the most sensitive to the lowermost layers of the troposphere in agreement with the DOF. The altitude of the maximum of the averaging kernels for the TROPO and the UTLS columns is similar for the three products. Table 5

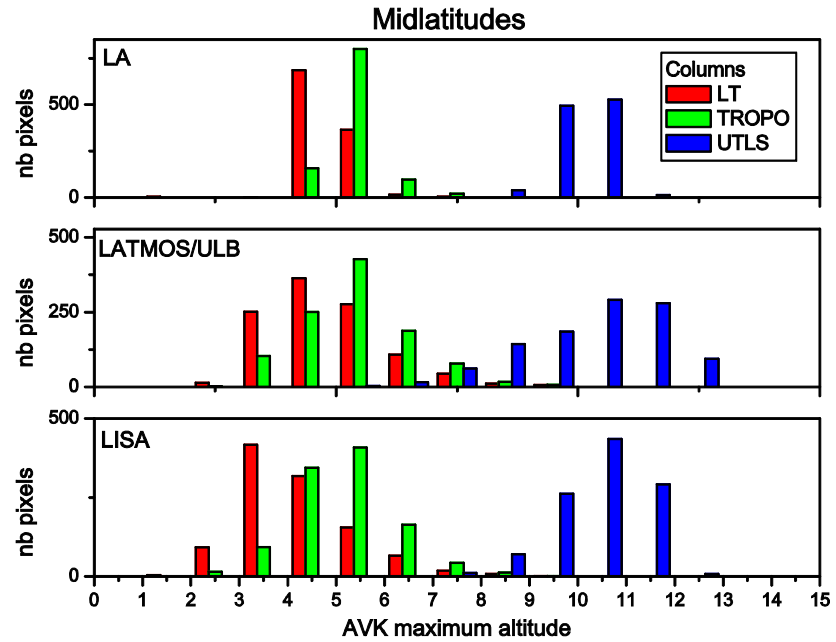

Fig. 2. Distribution of the altitude, in $\mathrm{km}$, of the averaging kernels of the LT, TROPO and UTLS partial columns of ozone given over the set of pixels selected for the validation. The distribution for the LA, LATMOS/ULB and LISA products are presented in the top, middle and bottom panels, respectively.

reports the difference in the altitude of the maximum of averaging kernels between winter and summer. As expected, the averaging kernels peak at lower altitudes during summer when the thermal conditions lead to a better sensitivity to the lower troposphere. For winter conditions, the three products are rather similar. In the tropics, the three products are the most sensitive close to $5 \mathrm{~km}$ in the LT on average (Table 5). The averaging kernels of the LA and LATMOS products peak at lower altitude in the troposphere compared to the LISA product (Table 5). The altitude of the maximum of 
sensitivity in the UTLS is different for each product ranging between $12.8 \mathrm{~km}$ (LA product) and $14.8 \mathrm{~km}$ (LATMOS/ULB product) (Table 5).

The ozone products are also characterized by their errors, although, as stated above, these are very much dependent on the retrieval constraints. Their consistency with the errors prescribed by the comparison with independent measurements will be discussed in Sect. 5. Here we consider the two main components of the error, the measurement noise error (Eq. 5) and the smoothing error (Eq. 6), that one can calculate directly from the retrieval process. The errors related to uncertain parameters of the radiative transfer model are more difficult to estimate properly. They usually contribute less than the two previous errors (Coheur et al., 2005; Boynard et al., 2009). We checked that the contribution of other sources of error (temperature, interferences with water vapor) contributed for less than $0.1 \mathrm{DU}(\leq 2 \%)$ for each partial column considered in this study and can then be neglected. Tables 6 and 7 summarize the mean errors in Dobson Unit (DU) and in percent on the different ozone columns for the midlatitudes and the tropics. The relevance of the errors calculated from the retrieval will be discussed in regards of the validation results in Sects. 5 and 6. Typically, we find that the errors calculated from the LA and the LISA products in the midlatitudes are likely slightly underestimated. In the tropics, the errors given for the LA product are underestimated except in the troposphere and the UTLS as well as the errors of the LISA product except in the lower troposphere. On the contrary, the retrieval errors for the LATMOS/ULB product appear to be too large in regard to the results from the validation exercise.

\section{Validation strategy}

\subsection{Ozonesonde measurements}

Ozonesondes provide in situ measurements of temperature, pressure, humidity and ozone at different stations around the world. The measured vertical profile of the different parameters reaches up to $30-35 \mathrm{~km}$ with a vertical resolution of $\sim 150 \mathrm{~m}$ for ozone. The ozonesondes data selected in the present validation exercise were obtained from different archives: WOUDC (http://www.woudc.org/), NOAACMDL (http://www.esrl.noaa.gov/gmd/dv/ftpdata.html), and SHADOZ (http://croc.gsfc.nasa.gov/shadoz/). Most of the sonde measurements use electrochemical concentration cell (ECC) technique, relying on the oxidation of ozone with a potassium iodine (KI) solution (Komhyr et al., 1995). The exceptions are the sondes used at Hohenpeissenberg (Brewer Mast type) and at the Naha station (carbone-iodine KC type). The accuracy of the ozone concentrations measured with the ozonesondes is about $\pm 5 \%$ (Deshler et al., 2008; Smit et al., 2007; Thompson et al., 2003).
Part of the sonde stations at the WOUDC measure overhead total ozone columns independently using Dobson or Brewer instruments. A correction factor is then calculated and applied to the coincident ozonesonde profile. The correction factor can also be used to screen the sonde data (Worden et al., 2007; Nassar et al., 2008; Keim et al., 2009). We used the same criterion than these previous studies to sort out the sonde data the most affected: we eliminated from the validation exercise the profiles for which the correction factor is more than $\pm 15 \%$. For the sonde data for which the correction factor was not given, we calculated it as the ratio of the integrated sonde and the OMI (Ozone Monitoring Instrument) total ozone column. The OMI data used are daily gridded columns (level-3), available at http: //mirador.gsfc.nasa.gov.

The ozonesondes used in this study are summarized in Table 2 for the midlatitudes and Table 3 for the tropics. The number of days of sonde measurement with coincidences with IASI pixels is indicated as well as the corresponding number of pixels. A selection of pixels similar to those used by Keim et al. (2009) is performed. The number of pixels considered for the validation is the subset of pixels common to the three products, which means the pixels that overcome all the filters of the three products. Note that additional validations have been conducted on sets of pixels defined independently for each product. The results of these additional validations are not discussed in details in the following but are mentioned to evaluate if the conclusions remain valid over larger numbers of pixels. We decided to restrict the study to a common set of pixels in order to keep consistency between the product validations and intercomparison. Actually, the number of pixels considered in the LATMOS/ULB product is usually half of the number available in the LA and LISA sets. Indeed, as mentioned in the description of each product, the LATMOS/ULB group uses the operational temperature profile of IASI, which, until April 2010, was only distributed by EUMETSAT for half of the pixels. The LA and the LISA groups use different approach to obtain the temperature profile (see the description of the products).

\subsection{Coincidence criteria}

In the literature, a range of coincidence criteria are used to select data for the validation of satellite measurements. They are defined considering the scale dependencies of the atmospheric variability of the measured species. However, the criteria are also moderated by the number of available data to validate: this number has to be statistically significant. The spatial coverage of IASI is dense and then allows one to consider tight spatial coincidence criterion consistent with the variability scale of tropospheric ozone. The coincidence criteria used for the present study are close to those defined by Keim et al. (2009), except for the time coincidence. The spatial coincidence criterion was chosen to be $\pm 110 \mathrm{~km}$. IASI has two overpasses per day, one in the morning (09:30 LT) 
Table 4. Degrees of Freedom (DOF) for different partial columns of ozone averaged over the sets of pixels in coincidence with the ozonesondes defined for each group (LA, LATMOS/ULB, LISA). The mean DOF are given in the midlatitudes and in the tropics separately as well as for winter and summer of the northern midlatitudes.

\begin{tabular}{|c|c|c|c|c|c|c|c|}
\hline & \multicolumn{7}{|c|}{ Mean degrees of freedom } \\
\hline & \multirow[t]{2}{*}{ TOTAL } & \multicolumn{2}{|r|}{ LT } & \multicolumn{2}{|c|}{ TROPO } & \multicolumn{2}{|c|}{ UTLS } \\
\hline & & winter & summer & winter & summer & winter & summer \\
\hline \multicolumn{8}{|c|}{ Midlatitudes } \\
\hline LA & 2.8 & 0.3 & 0.4 & 0.7 & 0.9 & 0.9 & 0.9 \\
\hline LATMOS/ULB & 3.3 & 0.2 & 0.4 & 0.7 & 1.0 & 0.9 & 1.0 \\
\hline LISA & 3.2 & 0.4 & 0.6 & 1.0 & 1.2 & 0.9 & 1.0 \\
\hline \multicolumn{8}{|c|}{ Tropics } \\
\hline LA & 2.8 & & 0.4 & & .4 & & 1.2 \\
\hline LATMOS/ULB & 3.7 & & 0.4 & & 6 & & 1.4 \\
\hline LISA & 3.2 & & 0.7 & & 6 & & 0.9 \\
\hline
\end{tabular}

Table 5. Altitude, in km, of the maximum of the averaging kernel (AVK) of different partial columns of ozone averaged over the sets of pixels in coincidence with the ozonesondes defined for each group (LA, LATMOS/ULB, LISA). The altitude is given in the midlatitudes and in the tropics separately as well as for winter and summer of the northern midlatitudes.

\begin{tabular}{|c|c|c|c|c|c|c|}
\hline & \multicolumn{6}{|c|}{ Mean altitude of the maximum of the AVK } \\
\hline & \multicolumn{2}{|c|}{ LT } & \multicolumn{2}{|c|}{ TROPO } & \multicolumn{2}{|c|}{ UTLS } \\
\hline & winter & summer & winter & summer & winter & summer \\
\hline \multicolumn{7}{|c|}{ Midlatitudes } \\
\hline LA & 5.3 & 4.6 & 6.1 & 5.5 & 9.6 & 10.1 \\
\hline LATMOS/ULB & 5.8 & 4.1 & 6.4 & 4.7 & 8.6 & 10.6 \\
\hline LISA & 5.1 & 3.5 & 6.0 & 4.4 & 9.3 & 10.3 \\
\hline \multicolumn{7}{|c|}{ Tropics } \\
\hline LA & \multicolumn{2}{|c|}{5.2} & \multicolumn{2}{|c|}{7.4} & \multicolumn{2}{|c|}{12.8} \\
\hline LATMOS/ULB & \multicolumn{2}{|c|}{5.0} & \multicolumn{2}{|c|}{7.5} & \multicolumn{2}{|c|}{14.8} \\
\hline LISA & \multicolumn{2}{|c|}{4.9} & \multicolumn{2}{|c|}{8.3} & \multicolumn{2}{|c|}{13.6} \\
\hline
\end{tabular}

and one in the evening (21:30 LT). We noticed that retrieved profiles could be significantly different between the morning and the evening and then different from the sonde profiles when the time span was the largest (typically with the evening profile when sonde measurement is performed in the morning). We then chose to set the temporal coincidence criterion at $7 \mathrm{~h}$. As most of the sonde measurements are performed in the morning (local time), this means that most of the pixels considered in this validation exercise correspond to pixels of the morning overpass of IASI. We checked a posteriori that the biases between the ozonesonde measurements and the IASI observations are not correlated with the time difference between the sonde and IASI measurements. The number of pixels used for the validation is summarized in Tables 2 and 3.

\subsection{Comparison methodology}

The vertical ozone profiles measured by the ozonesondes and retrieved from IASI are not provided with the same vertical resolution. The ozonesonde profiles are much more resolved $(\sim 150 \mathrm{~m})$ compared to the IASI profiles. A proper method for the intercomparison of remote sensing profile with different resolution is described by Rodgers (2000) and Rodgers and Connor (2003) and broadly used for validation purposes (e.g. Worden et al., 2007; Keim et al., 2009). The averaging kernels of IASI ( $\left.A_{\text {IASI }}\right)$ are then applied to the coincident ozonesonde profiles $\left(x_{\text {sonde }}\right)$ for each pixel of each product separately following Eq. (7).

$\boldsymbol{x}_{\text {smooth }}=\boldsymbol{x}_{\mathrm{ap}}+\mathbf{A}_{\text {IASI }}\left(\boldsymbol{x}_{\text {sonde }}-\boldsymbol{x}_{\text {ap }}\right)$ 
Table 6. Statistics of the comparison between the three IASI ozone products and the ozonesondes for the midlatitudes. The bias (IASIsondes), the rms of this difference and the corresponding correlation coefficient are given for different partial columns. Theoretical total error estimates (Stot) is also displayed for the corresponding partial columns of ozone. The bias, the rms, and Stot are given in DU and in percent (in parenthesis).

\begin{tabular}{|c|c|c|c|c|c|c|c|c|c|c|c|c|}
\hline & \multicolumn{4}{|c|}{ LA } & \multicolumn{4}{|c|}{ LATMOS/ULB } & \multicolumn{4}{|c|}{ LISA } \\
\hline & Bias & $\mathrm{rms}$ & Stot & $R$ & Bias & $\mathrm{rms}$ & Stot & $R$ & Bias & $\mathrm{rms}$ & Stot & $R$ \\
\hline LT & $\begin{array}{c}0.4 \\
(2.4)\end{array}$ & $\begin{array}{c}2.1 \\
(12.0)\end{array}$ & $\begin{array}{c}1.8 \\
(9.9)\end{array}$ & 0.49 & $\begin{array}{c}-1.4 \\
(-8.1)\end{array}$ & $\begin{array}{c}2.9 \\
(16.6)\end{array}$ & $\begin{array}{c}2.4 \\
(15.9)\end{array}$ & 0.60 & $\begin{array}{l}-0.38 \\
(-2.0)\end{array}$ & $\begin{array}{c}3.5 \\
(17.5)\end{array}$ & $\begin{array}{c}2.3 \\
(12.3)\end{array}$ & 0.69 \\
\hline TROPO & $\begin{array}{c}4.0 \\
(11.3)\end{array}$ & $\begin{array}{c}3.9 \\
(11.2)\end{array}$ & $\begin{array}{c}2.9 \\
(7.5)\end{array}$ & 0.82 & $\begin{array}{c}0.6 \\
(1.6)\end{array}$ & $\begin{array}{c}5.5 \\
(15.3)\end{array}$ & $\begin{array}{c}4.9 \\
(14.0)\end{array}$ & 0.82 & $\begin{array}{c}1.0 \\
(2.6)\end{array}$ & $\begin{array}{c}6.1 \\
(16.0)\end{array}$ & $\begin{array}{c}4.1 \\
(11.1)\end{array}$ & 0.83 \\
\hline UTLS & $\begin{array}{c}6.5 \\
(13.5)\end{array}$ & $\begin{array}{c}7.1 \\
(14.7)\end{array}$ & $\begin{array}{c}4.5 \\
(8.9)\end{array}$ & 0.93 & $\begin{array}{c}5.6 \\
(10.6)\end{array}$ & $\begin{array}{c}7.9 \\
(15.1)\end{array}$ & $\begin{array}{c}6.0 \\
(11.2)\end{array}$ & 0.93 & $\begin{array}{c}6.3 \\
(13.2)\end{array}$ & $\begin{array}{c}8.9 \\
(18.6)\end{array}$ & $\begin{array}{c}5.1 \\
(10.8)\end{array}$ & 0.90 \\
\hline STRATO & $\begin{array}{c}2.4 \\
(1.2)\end{array}$ & $\begin{array}{c}9.4 \\
(4.8)\end{array}$ & $\begin{array}{c}7.1 \\
(3.6)\end{array}$ & 0.91 & $\begin{array}{c}4.8 \\
(2.4)\end{array}$ & $\begin{array}{l}10.9 \\
(5.4)\end{array}$ & $\begin{array}{l}11.3 \\
(5.5)\end{array}$ & 0.91 & $\begin{array}{l}-4.9 \\
(-2.5)\end{array}$ & $\begin{array}{l}11.1 \\
(5.7)\end{array}$ & $\begin{array}{c}4.4 \\
(2.3)\end{array}$ & 0.88 \\
\hline UPTO30 & $\begin{array}{l}10.0 \\
(3.8)\end{array}$ & $\begin{array}{l}13.5 \\
(5.0)\end{array}$ & $\begin{array}{c}8.6 \\
(3.1)\end{array}$ & 0.94 & $\begin{array}{c}8.7 \\
(3.3)\end{array}$ & $\begin{array}{l}13.6 \\
(5.1)\end{array}$ & $\begin{array}{l}19.2 \\
(7.0)\end{array}$ & 0.94 & $\begin{array}{c}1.2 \\
(0.5)\end{array}$ & $\begin{array}{l}13.6 \\
(5.1)\end{array}$ & $\begin{array}{c}7.2 \\
(2.7)\end{array}$ & 0.94 \\
\hline
\end{tabular}

$\boldsymbol{x}_{\mathrm{ap}}$ is the a priori profile used in the retrieval. If the ozonesonde profile is assumed to be the true atmospheric state, the smoothed sonde profile, $\boldsymbol{x}_{\text {smooth }}$, represents the profile that would be retrieved from IASI without any other errors (e.g. measurement noise). Note that the ozonesonde profile $\boldsymbol{x}_{\text {sonde }}$ corresponds to the sonde profile mapped to the retrieval grid which is different for each product. The sonde profiles do not cover the entire altitude range considered by the retrieval. The amount of ozone above the balloon burst is taken from the a priori profile of each product. In the following, the discussed quantities related to this mapped profile are referred to as "raw" quantities.

The difference between the smoothed sonde profile and the retrieved profile is a means to characterise the performances of the retrieval. This is the case when enough information is contained in the observation and when the retrieval scheme allows one to extract this information. Actually one has to keep in mind that the smoothed sonde profile is partly contaminated by a priori information. This can distort the interpretation of the comparison in some cases (see the discussion in Keim et al., 2009). A comparison with the raw sonde profile can be useful to evaluate the impact of the contamination by the a priori.

In the current work, we compare profiles but the performances of the products are discussed in terms of partial columns. Indeed, due to the small number of independent information in the profile it is preferable to consider partial columns. Most of the columns presented here contain around one piece of information (one degree of freedom).

\section{Validation results for the midlatitudes}

In this section we present the statistical analysis of the comparison between the ozonesonde measurements and the LA, LATMOS/ULB and LISA products in the midlatitudes. The analysis is done with the set of pixels given in Table 2.

\subsection{Global analysis}

The direct output of each software is the ozone profile. We then first compare the retrieved ozone profile with the raw and smoothed ozonesonde profiles. Figures 3 to 5 show the comparison of the mean profiles averaged over all the pixels for the LA, LATMOS/ULB and LISA products respectively. The relative difference (or bias) between the retrieved profile and the raw (black) and the smoothed (blue) ozonesonde profiles are displayed as well as the root mean square of the differences (rmsd). The shape of the bias and rmsd profiles between the comparison with the raw and the smoothed profiles is rather similar and do not reveal any inconsistency. The bias and the rmsd obtained when comparing with the smoothed profiles are usually smaller than when the retrieved profiles are compared with the raw profiles. This is due to the partial removal of the systematic (bias) and random (rms) differences due to the smoothing error when ozonesonde profiles are convolved by the averaging kernel of the retrievals using Eq. (7). In the following, only the comparison with the smoothed ozonesonde profiles (or partial columns) is discussed in details. The main feature that comes out of the comparison of the profiles is a general tendency of the three products to overestimate the ozone in the upper troposphere up to $25 \%$. In the other regions (lower troposphere and stratosphere), the agreement is usually better than $10 \%$. 
Table 7. Same as Table 6 but for the tropics.

\begin{tabular}{|c|c|c|c|c|c|c|c|c|c|c|c|c|}
\hline & \multicolumn{4}{|c|}{ LA } & \multicolumn{4}{|c|}{ LATMOS/ULB } & \multicolumn{4}{|c|}{ LISA } \\
\hline & Bias & $\mathrm{rms}$ & Stot & $R$ & Bias & $\mathrm{rms}$ & Stot & $R$ & Bias & $\mathrm{rms}$ & Stot & $R$ \\
\hline LT & $\begin{array}{c}3.8 \\
(17.2)\end{array}$ & $\begin{array}{c}2.4 \\
(10.9)\end{array}$ & $\begin{array}{c}2.3 \\
(8.6)\end{array}$ & 0.64 & $\begin{array}{l}-1.4 \\
(-6.7)\end{array}$ & $\begin{array}{c}2.2 \\
(10.6)\end{array}$ & $\begin{array}{c}3.4 \\
(17.4)\end{array}$ & 0.86 & $\begin{array}{c}-1.5 \\
(-6.2)\end{array}$ & $\begin{array}{c}2.5 \\
(10.6)\end{array}$ & $\begin{array}{c}2.1 \\
(9.3)\end{array}$ & 0.86 \\
\hline TROPO & $\begin{array}{c}4.8 \\
(3.8)\end{array}$ & $\begin{array}{c}3.3 \\
(9.5)\end{array}$ & $\begin{array}{c}4.9 \\
(12.4)\end{array}$ & 0.93 & $\begin{array}{c}1.2 \\
(3.6)\end{array}$ & $\begin{array}{c}3.1 \\
(9.2)\end{array}$ & $\begin{array}{c}8.4 \\
(24.0)\end{array}$ & 0.95 & $\begin{array}{c}3.5 \\
(9.8)\end{array}$ & $\begin{array}{c}3.9 \\
(11.0)\end{array}$ & $\begin{array}{c}2.5 \\
(6.5)\end{array}$ & 0.91 \\
\hline UTLS & $\begin{array}{c}4.7 \\
(17.5)\end{array}$ & $\begin{array}{c}5.2 \\
(19.3)\end{array}$ & $\begin{array}{c}5.5 \\
(17.9)\end{array}$ & 0.81 & $\begin{array}{c}3.8 \\
(13.5)\end{array}$ & $\begin{array}{c}4.4 \\
(15.6)\end{array}$ & $\begin{array}{c}6.7 \\
(21.4)\end{array}$ & 0.88 & $\begin{array}{c}6.1 \\
(23.6)\end{array}$ & $\begin{array}{c}2.9 \\
(11.4)\end{array}$ & $\begin{array}{c}1.6 \\
(5.1)\end{array}$ & 0.92 \\
\hline STRATO & $\begin{array}{l}11.1 \\
(7.1)\end{array}$ & $\begin{array}{c}8.3 \\
(5.3)\end{array}$ & $\begin{array}{c}6.7 \\
(4.0)\end{array}$ & 0.74 & $\begin{array}{c}9.1 \\
(5.7)\end{array}$ & $\begin{array}{c}9.2 \\
(5.8)\end{array}$ & $\begin{array}{c}8.9 \\
(5.3)\end{array}$ & 0.76 & $\begin{array}{l}-3.3 \\
(-2.1)\end{array}$ & $\begin{array}{c}8.7 \\
(5.5)\end{array}$ & $\begin{array}{c}2.7 \\
(1.8)\end{array}$ & 0.77 \\
\hline UPTO30 & $\begin{array}{l}15.8 \\
(8.2)\end{array}$ & $\begin{array}{c}9.9 \\
(5.2)\end{array}$ & $\begin{array}{c}8.3 \\
(4.0)\end{array}$ & 0.84 & $\begin{array}{c}8.9 \\
(4.7)\end{array}$ & $\begin{array}{l}10.3 \\
(5.4)\end{array}$ & $\begin{array}{l}16.7 \\
(8.3)\end{array}$ & 0.83 & $\begin{array}{c}0.2 \\
(0.1)\end{array}$ & $\begin{array}{c}9.0 \\
(4.6)\end{array}$ & $\begin{array}{c}3.7 \\
(1.9)\end{array}$ & 0.89 \\
\hline
\end{tabular}
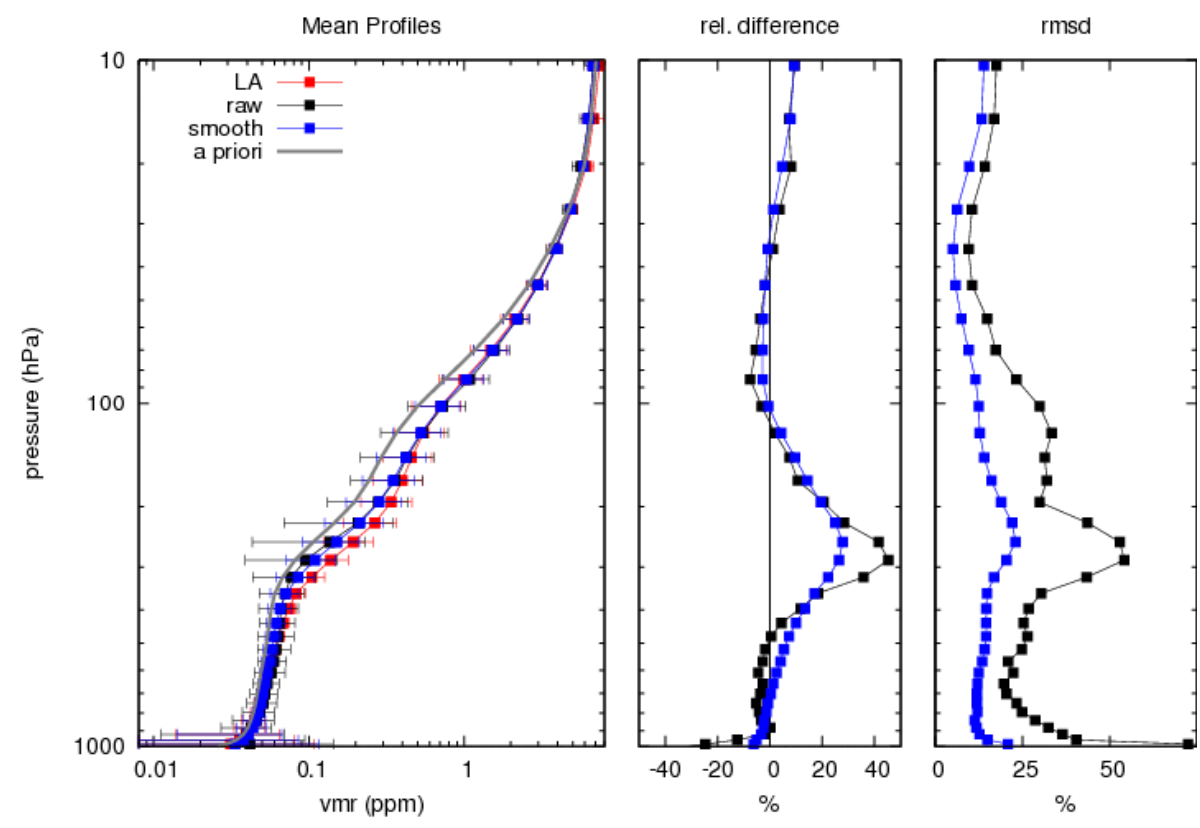

Fig. 3. Left panel: mean vertical profiles of ozone mixing ratios retrieved with the LA algorithm (red), measured by the ozonesondes (black), measured by the ozonesondes but smoothed with the averaging kernels of the LA retrieval (blue). The average is done over the entire validation period (year 2008) and for the midlatitudes. The mean a priori profile is also plotted (gray). Middle: vertical profiles of the difference between the retrieved profile and the measured (black) or measured and smoothed (blue) profile, given in percent. Right panel: vertical profiles of the rms of the previous differences, given in percent.

In addition to profiles, we usually prefer to refer to partial columns due to the lack of vertical information in the retrieval. The partial columns considered here are the same than those described in Sect. 3. The results of the statistical comparison between the retrieved and the smoothed partial columns are summarized in Table 6 in terms of bias, rms and correlation coefficient for the three products. Following the conclusion of the profiles comparison, the largest difference between the retrieval and the ozonesondes is visible in the UTLS column. The ozone is systematically overestimated by the retrievals. The bias in the UTLS ranges between 10 and $15 \%$ (Table 6). Reasons for this overestimation are not completely obvious but tentative of explanations are provided here:

- First of all, part of the biases found in the UTLS is likely related to the constraint on the retrieval that gives the maximum of freedom for the solution to vary within this altitude range. In the case of optimal estimation retrievals (LA and LATMOS/ULB products), this region 

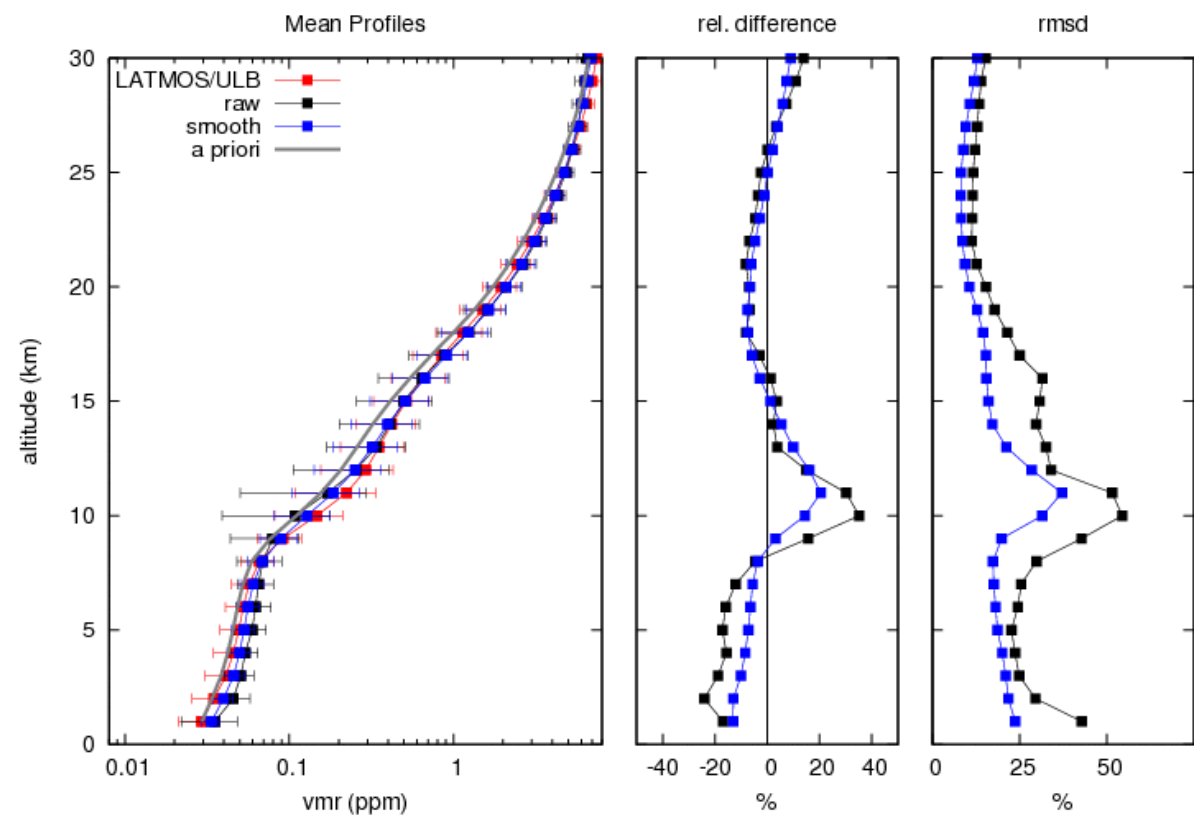

Fig. 4. Same as Fig. 3 for the LATMOS/ULB product.
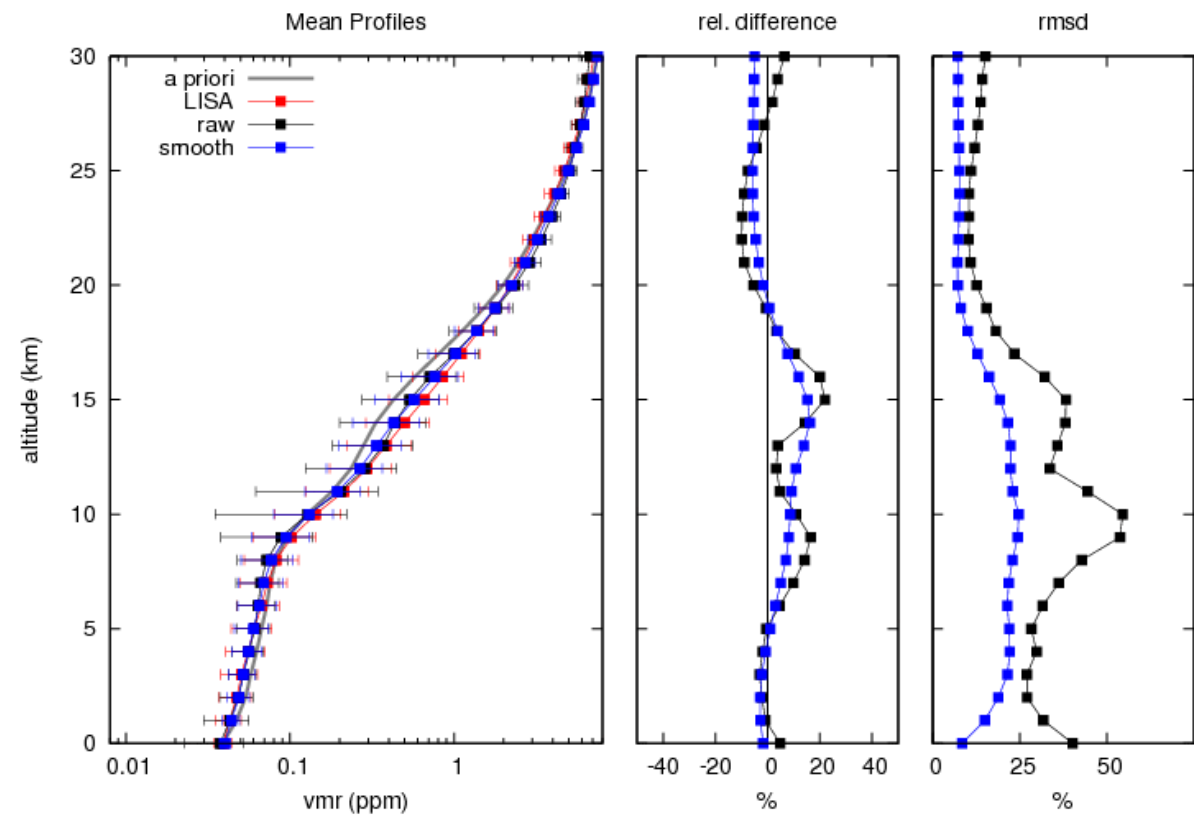

Fig. 5. Same as Fig. 3 for the LISA product.

is by nature the UTLS region, where the ozone is the most variable. For the case of LISA, the constraint is based on a mathematical regularization of the solution. However, the developed altitude-dependent regularization gives also a maximum of freedom to the solution in the ULTS by construction. Systematic biases related to the radiative transfer are therefore preferentially corrected by $\mathrm{O}_{3}$ biases in the UTLS.
- As a related point, if one compares the a priori profiles different for each group - to the mean ozonesondes profiles, it appears that the a priori profiles underestimate ozone values in the stratosphere and/or in the UTLS compared to the ozonesondes (Figs. 3 to 5). The difference in the stratosphere is generally corrected during the retrieval leading to a rather good agreement of the retrieved quantities with the ozonesondes. As the UTLS 
and the stratosphere are not completely independent according to the averaging kernels (not shown), the freedom accessible for the solution is not sufficient enough to correct independently the stratospheric and the UTLS parts. Then, it seems that the retrieved quantities of ozone in the UTLS are pulled towards larger values to allow correcting the stratosphere.

- Spectroscopic uncertainties on ozone lines can be a factor as well (we recall that the three products are based on the same spectroscopic data). Several studies comparing atmospheric measurements of ozone from UV and IR instruments (total columns) report on a bias of 3-4\% on average (Schneider et al., 2008; Boynard et al., 2009; Viatte et al., 2011). If the bias is identical for all the spectral lines, one expects a similar bias all over the profile, moderated by the strength of the constraint. If an intensity dependency of the reference line intensity errors exists, this could lead also to an altitude dependency of the retrieval bias. Indeed, absorption lines with different intensities are sensitive to $\mathrm{O}_{3}$ variations at different altitudes. Moreover, systematic errors on the linewidth from the database, or an inadequate lineshape model (all software use here a Voigt lineshape) could also imply altitude dependent biases because of compensatory effects.

- Finally, systematic problems in the radiative transfer could also imply biases in the retrieval but they are more difficult to identify. Moreover, it is worth noting that different radiative transfer models are used for the retrievals, this partly overcomes systematic radiative transfer errors.

Note that ozone retrievals from other infrared nadir sounders like TES are also biased high in the UTLS region (Worden et al., 2007; Nassar et al., 2008; Boxe et al., 2010).

The comparison for the other partial columns does not present such large biases. The bias is usually smaller than $5 \%$ (Table 6). However, larger differences are observed for some columns. The bias on the tropospheric column (TROPO) of the LA product is positive and reaches $11.3 \%$. The LATMOS/ULB product shows a negative bias in the lower troposphere (LT) of $8 \%$. This negative bias compensates partly the positive bias in the upper troposphere and leads to an overall small bias $(<2 \%)$ on the tropospheric ozone column, which is the most meaningful from the information content analysis (DOF close to 1). Except for the UTLS partial column, the LISA product does not show bias larger than $5 \%$. The correlation between the retrieved partial columns and the smoothed ozonesonde columns is significant (larger than 0.8) for most of the partial columns considered (Table 6) and similar between the different products. Nevertheless, the correlation coefficient of the LT column is degraded for the three products and ranges from 0.5 for the LA product to 0.7 for the LISA product. This lower correlation coefficients and larger biases for the LT column are expected since LT does not represent a single piece of information with DOF lower than 0.6 for the three products.

The rms of the difference between the retrieved and the smoothed columns (Table 6) gives an estimation of the random error on the columns (Keim et al., 2009). The rms is given in Table 6 for each partial column and each product. The LATMOS/ULB and the LISA products present similar rms for the different partial columns. The LA product gives smaller rms in the lower troposphere and in the entire troposphere. The difference in the rms of the three products reveals the difference in the strength of the constraint in the troposphere for the retrieval and is related to the ability of the retrieval to capture the natural variability of ozone. This point is discussed in the next paragraph. As the rms gives an estimation of the random error of the product, it is interesting to compare it with the estimation of the error calculated from the retrieval (see Sect. 3 and Table 6). Note that the error estimated from the rms includes not only the error estimate from the IASI observations but also the error on the ozonesonde measurements (of the order of $5 \%$ ) and then is naturally slightly larger than the error estimate for IASI. For the LATMOS/ULB product, the theoretical error from the retrieval is in good agreement with the error estimated by the comparison with the ozonesondes (Table 6). In the case of the LA and the LISA products, the theoretical error seems partly underestimated, especially for partial columns from the TROPO to the UPTO30 columns (Table 6). Note that we also processed all the statistical analyses with the ozonesondes not convolved with the averaging kernels of the retrievals (not shown). The results are consistent in terms of biases and rms, with values slightly larger as expected. The main difference arises on the correlation coefficients in the troposphere that drops down to 0.4 for the LT columns and to 0.7 for the TROPO columns of the three products.

The last point we considered for the global analysis is the ability of each product to reproduce the natural variability of ozone. This variability is estimated for each partial column by the $1 \sigma$ standard deviation of the annual mean of the raw ozonesonde column. The "theoretical" or expected variability from the satellite observation is given by the $1 \sigma$ standard deviation of the annual mean of the smoothed ozonesonde column (Eq. 7) and named smoothed variability in the following. But in reality other errors than the smoothing errors contribute (Eq. 3.16 in Rodgers, 2000) and explain the differences between the smoothed and the retrieved variability. The retrieved variability is then usually larger. Moreover, one expects that both the smoothed and retrieved variability are equal or smaller than the natural variability due to the constraint applied during the retrieval. This is the case for the UTLS, STRATO, and UPTO30 columns of the three products (Figs. 6 to 8, upper panel). In the case of the STRATO and the UPTO30 columns, the three variabilities - natural, smoothed and retrieved - are very similar. In the case of the UTLS columns, the smoothed and the retrieved variabilities 
year

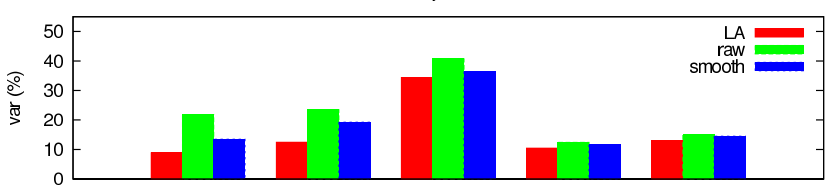

DJF
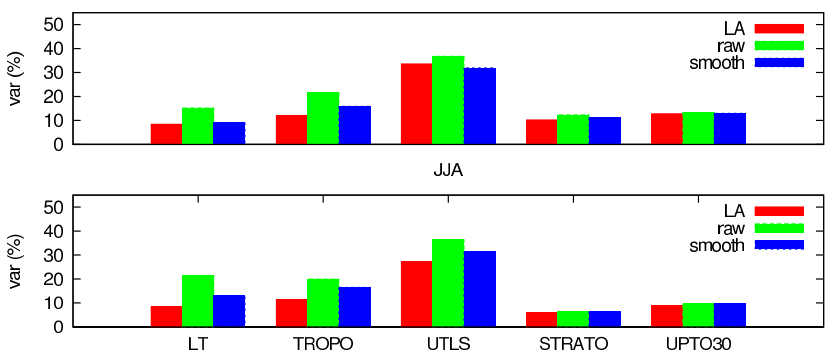

Fig. 6. Standard deviation (\%) of the mean partial columns of ozone averaged over the set of pixels defined for the validation in the case of the LA product over the entire year 2008 (top panel), over winter (middle panel), and over summer (bottom panel). The standard deviation is given for the retrieved columns, the measured ozonesonde columns and the smoothed ozonesonde columns. It represents the variability of ozone. The definition of the partial columns is given in Sect. 3.

over the year are significantly smaller than the natural variability for the three products. For the troposphere, each product behaves differently. In the LA product, the retrieved variability is lower than the natural variability, as it is expected, but it is systematically and significantly lower than the smoothed variability (Fig. 6, upper panel). In the LATMOS/ULB product (Fig. 7, upper panel), the smoothed variability is slightly smaller than the natural variability as expected, but the retrieved variability is slightly larger than the natural variability. In the LISA product (Fig. 8, upper panel), both the retrieved and the smoothed variability are slightly larger than the natural variability. A winter/summer analysis was performed and the results are displayed in the middle and bottom panels of Figs. 6 to 8. The LA product does not show any seasonal effect whereas the LATMOS/ULB and LISA products do. Actually, the retrieved variability from the LATMOS/ULB product is significantly too large compared to the natural and smoothed variabilities in winter, especially in the lower troposphere (Fig. 7, middle panel). In summer, small or no difference with the natural variability is visible (Fig. 7, bottom panel). The LISA product shows too large retrieved and smoothed variabilities in winter for both the LT and the TROPO columns (Fig. 8, middle panel). In summer, the smoothed and retrieved variabilities are very close to the natural variability prescribed by the ozonesondes (Fig. 8, bottom panel). The difference between the behaviors of the three products has to be related to the difference in the constraint used by each group. If the constraint is too weak, i.e. the balance between the weight given to the information coming from the a priori or from the observation

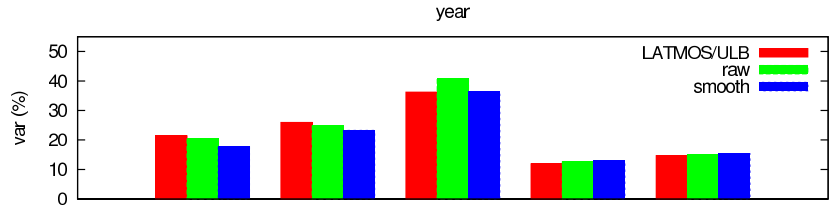

D.JF
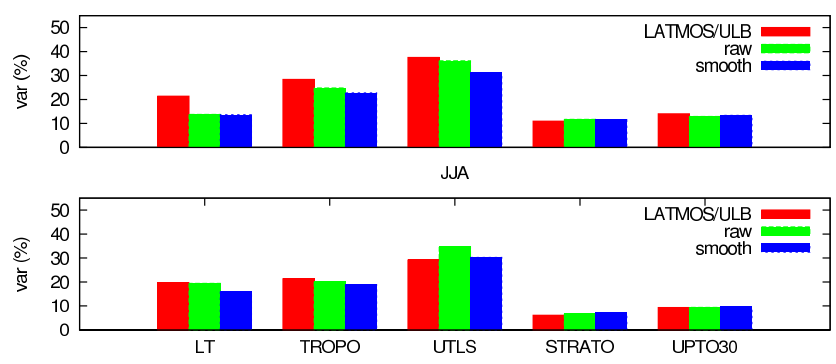

Fig. 7. Same as Fig. 6 for the LATMOS/ULB product.

is shifted towards the a priori, not all the information contained in the observation is used, the solution of the retrieval tends to stay too close to the a priori. The deduced variability is then underestimated. This is typically the case of the LA product. This also has to be related to the weaker and likely underestimated rms and then error estimate obtained in the comparison with the sondes (Table 6). On the contrary, if the constraint is too strong towards the observation, i.e. the balance between the weight given to the information coming from the a priori or from the observation is shifted towards the observations, part of the retrieved information come from the noise in the spectrum. The deduced variability is then overestimated. This is typically the case in winter for the LATMOS/ULB and the LISA products. The poorer performance of the LISA product to reproduce the natural variability of ozone in winter is not surprising. Indeed, the retrieval processing has been designed with the objective of monitoring air quality in the lowermost troposphere and is preferentially used to analyze summer periods when ozone pollution events occur in the midlatitudes. The regularization and the a priori used for the retrieval have then been developed for summer conditions and to retrieve the maximum of information in the lower troposphere (Eremenko et al., 2008; Dufour et al., 2010), and are then not fully suited for the retrieval in winter.

As mentionned in Sect. 4.1, validation on independent sets of pixels (2683 pixels for the LA product and 2950 for the LISA product) was performed. The conclusions of the validation are very similar to the ones obtained on the restricted set of pixels and confirm the statistical meaning of the validation reported in the present study. The main difference concerns the correlation in the LT: the correlation coefficient increases when a larger number of pixels is considered $(0.66$ for the LA product against 0.49 , and 0.83 for the LISA product against 0.69 ). One can also notice that the extended set of pixels usually includes more data during winter and then confirms the moderate performances of the LISA 
year

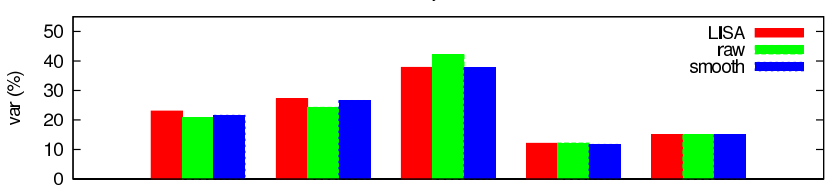

DJF

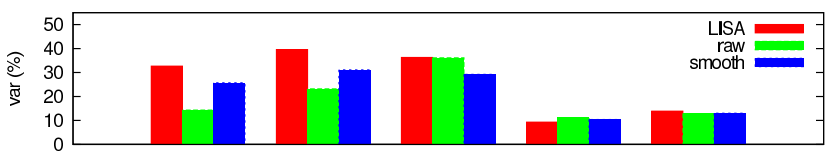

JA

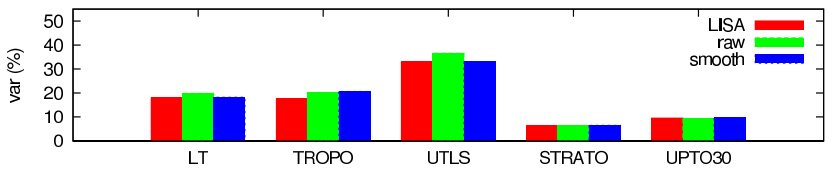

Fig. 8. Same as Fig. 6 for the LISA product.

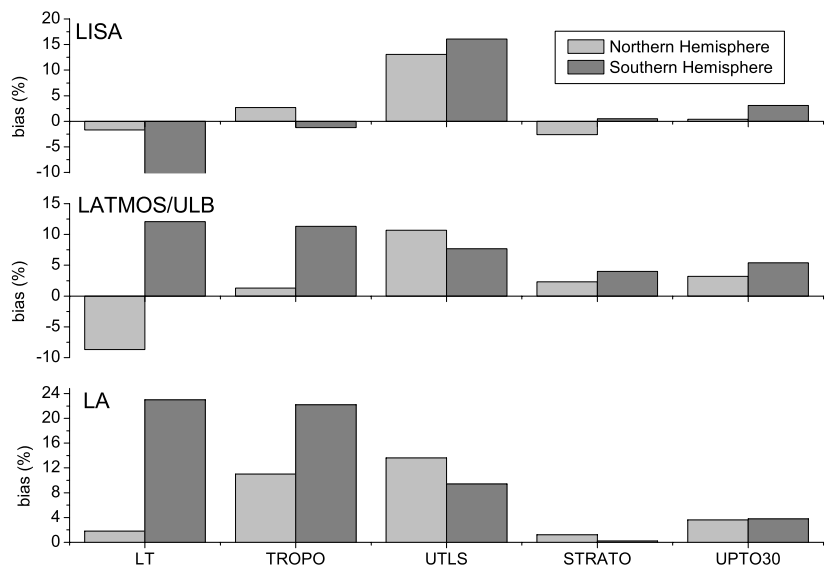

Fig. 9. Bias between the retrieved partial columns and the smoothed ozonesonde columns for the three products. A comparison between the northern (light gray) and the southern (gray) midlatitudes is given. The definition of the partial columns is given in Sect. 3 .

product in reproducing the natural variability of ozone during winter.

\subsection{Hemispheric analysis}

At the time the present study was performed, ozonesonde measurements at two stations of the southern hemisphere that present coincidences with the three products (Table 2) were available. Specific comparisons between the retrieved partial columns and the smoothed partial columns have been conducted separately for the northern and southern midlatitudes. The results of the comparisons are displayed in Fig. 9. In general, the performances of the three products in reproducing ozonesondes measurement are degraded in the southern midlatitudes, especially considering the bias. For the LA product, the region the most affected is the troposphere. The bias of the LT and TROPO columns is strongly increased

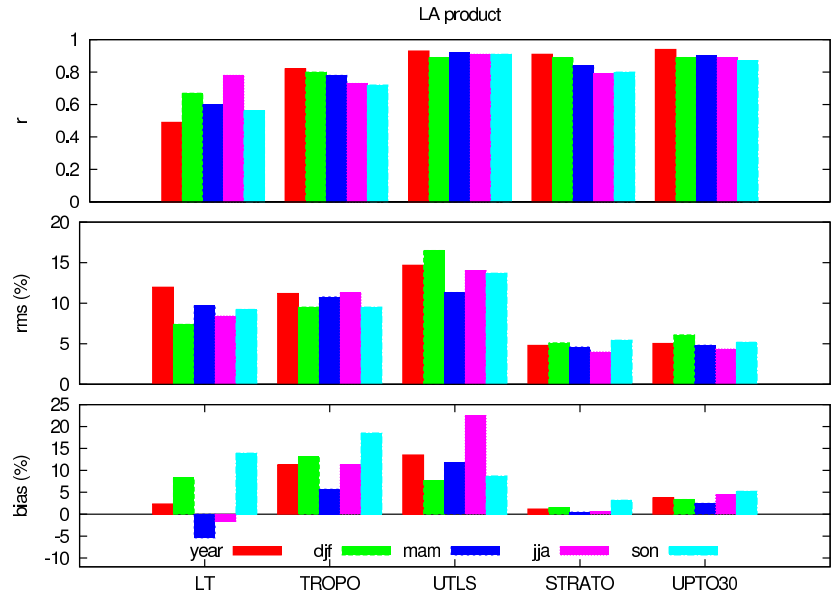

Fig. 10. Seasonal variation in the northern midlatitudes of bias (bottom panel), rms (middle panel) and correlation coefficient ( $r$, top panel) for the comparison of the LA retrieved partial columns and the smoothed ozonesonde partial columns. The definition of the partial columns is given in Sect. 3 .

compared to the northern midlatitudes: the bias reaches more than $20 \%$ (bottom panel in Fig. 9). For the LATMOS/ULB and the LISA products, the situation is more contrasted. However, it is worth noting that the number of measurements available in the southern midlatitudes is much less than in the northern midlatitudes (Table 2).

\subsection{Seasonal analysis}

In the northern hemisphere, enough ozonesonde measurements and coincidences with IASI observations are available to do a seasonal comparison of statistical significance. Figures 10 to 12 show the bias, the rms, and the correlation coefficient calculated for each season and compare to the annual statistics for LA, LATMOS/ULB and LISA products, respectively. The main feature that comes out of the seasonal comparison is the increase of the bias in the UTLS during summer for the three products. No such behavior is noticed for the rms and the correlation coefficient. No significant seasonal variations in the comparison of the ozonesonde and the retrieved ozone are visible for the STRATO and UPTO30 partial columns for the three products, except that the correlation coefficient of the three products is usually larger in winter for the STRATO columns. For the two tropospheric columns (LT and TROPO), there are more seasonal variability in the comparison and the tendency is different from one product to another. For the LA product, the bias of the LT partial column is variable and change sign depending on the season (Fig. 10). For the TROPO column, positive biases larger than $10 \%$ occur all the seasons except in spring when the bias is smaller, due to compensation effects with the negative bias in the lower troposphere (Fig. 10). The results of the comparison for the LATMOS/ULB product (Fig. 11) show 


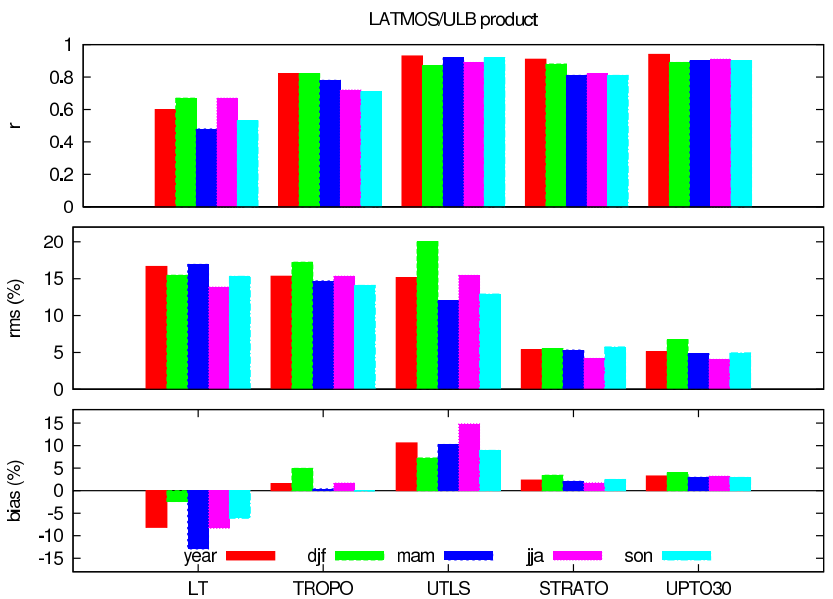

Fig. 11. Same as Fig. 10 for the LATMOS/ULB product.

that the bias for the TROPO column remains very small for all the seasons $(<5 \%)$. No specific variations are noticed for the rms and the correlation coefficient. The comparison for the LT column shows a persistent negative bias all over the seasons, with a smaller bias in winter. One can notice that the largest bias in spring is associated with a larger rms and a smaller correlation coefficient (Fig. 11). Concerning the comparison with the LISA product (Fig. 12), as discussed in Sect. 5.1, the moderate performances in reproducing the natural variability in winter result in larger rms in winter for the LT, TROPO and UTLS columns. The errors to be considered for the LISA product in winter has to be larger than those estimated from the retrieval process to account for this. The rms for the other seasons is very similar. The bias remains very small in the lower troposphere and for the TROPO column $(<5 \%)$.

\section{Validation results for the tropics}

The validation done for the tropical latitudes is likely less robust that the one done for the midlatitudes for two reasons. The first reason is due to the number of available ozonesonde measurements in the tropics where they are less than in the midlatitudes (Table 3). The second reason rises in the particular shape of the ozone profile in the tropics, an "s-shape" profile that can lead to misbehavior during the retrieval or the smoothing processes. Indeed, the "s-shape" of the profile can be artificially accentuated either in the retrieved ozone profile or in the sonde profile smoothed with the averaging kernels. Figure 13 illustrates this effect in the two cases. The $1 \sigma$ standard deviation of the mean profiles is significantly larger towards the low values in the upper troposphere when the standard deviation of the mean retrieved profile for one ozonesonde station is compared to those of the corresponding raw sonde profile (right in Fig. 13) or when the standard deviation of the mean smoothed profile is compared to those

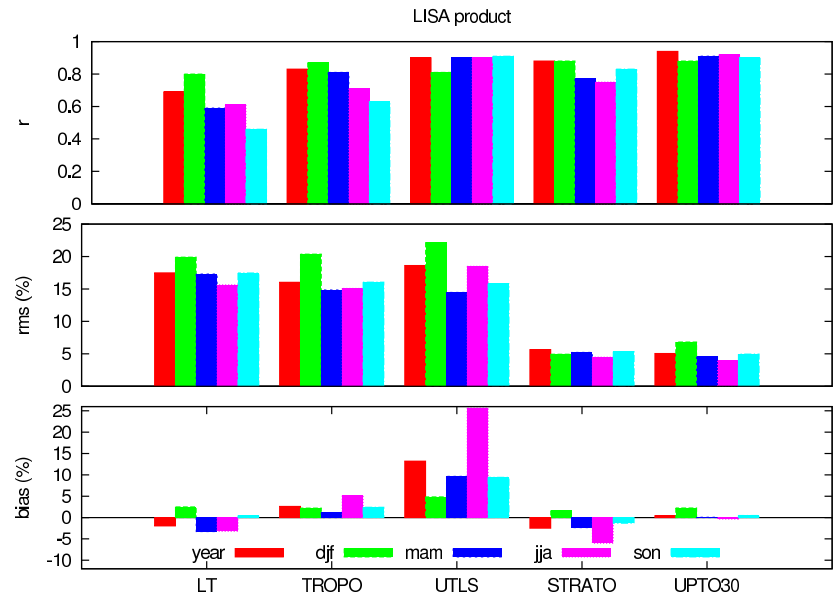

Fig. 12. Same as Fig. 10 for the LISA product.

of the corresponding raw sonde profile (left in Fig. 13). The most affected part of the profile is the upper troposphere, where the values of ozone, either retrieved or smoothed, are systematically underestimated and can become unrealistically low for some individual pixels. However, the resulting profiles remain reasonable when we consider the average over all the pixels from the current validation exercise. Typically, the LATMOS/ULB and the LISA products are mainly affected by this effect on the smoothed ozonesonde profiles whereas the LA product is mostly affected directly on the retrieved profiles. The bias calculated in the tropics can then be slightly overestimated especially in the upper troposphere.

In the following, we show the statistical analysis of the comparisons between the three products and the ozonesondes for different partial columns defined in Sect. 3. However, we checked the consistency of the results with those obtained when comparing with the raw ozonesondes. Table 8 summarizes the statistics of the comparison for the different columns and the three products. The LA product presents significant biases, up to $17.2 \%$, in the troposphere (LT and TROPO columns) and in the UTLS. The biases in the stratosphere and on the column up to $30 \mathrm{~km}$ are smaller but remain significant compared to the errors associated with the columns (Table 7). The correlation coefficient is close to or larger than 0.8 (Table 7) except for the LT and the STRATO columns for which it is smaller (0.64 and 0.74 respectively). The LATMOS/ULB product shows smaller biases for all the columns. A negative bias of similar magnitude than in the midlatitudes is calculated in the lower troposphere as well as in the UTLS region (Table 7). The bias for the TROPO column is small whereas the bias for the stratosphere and the column up to $30 \mathrm{~km}$ starts to become significant. The different partial columns are well correlated between the ozonesonde and the retrieval. Note that the errors prescribed from the retrieval are overestimated in the troposphere and the UTLS compared to the rms calculated from the comparison with the ozonesondes (Table 7). The LISA 

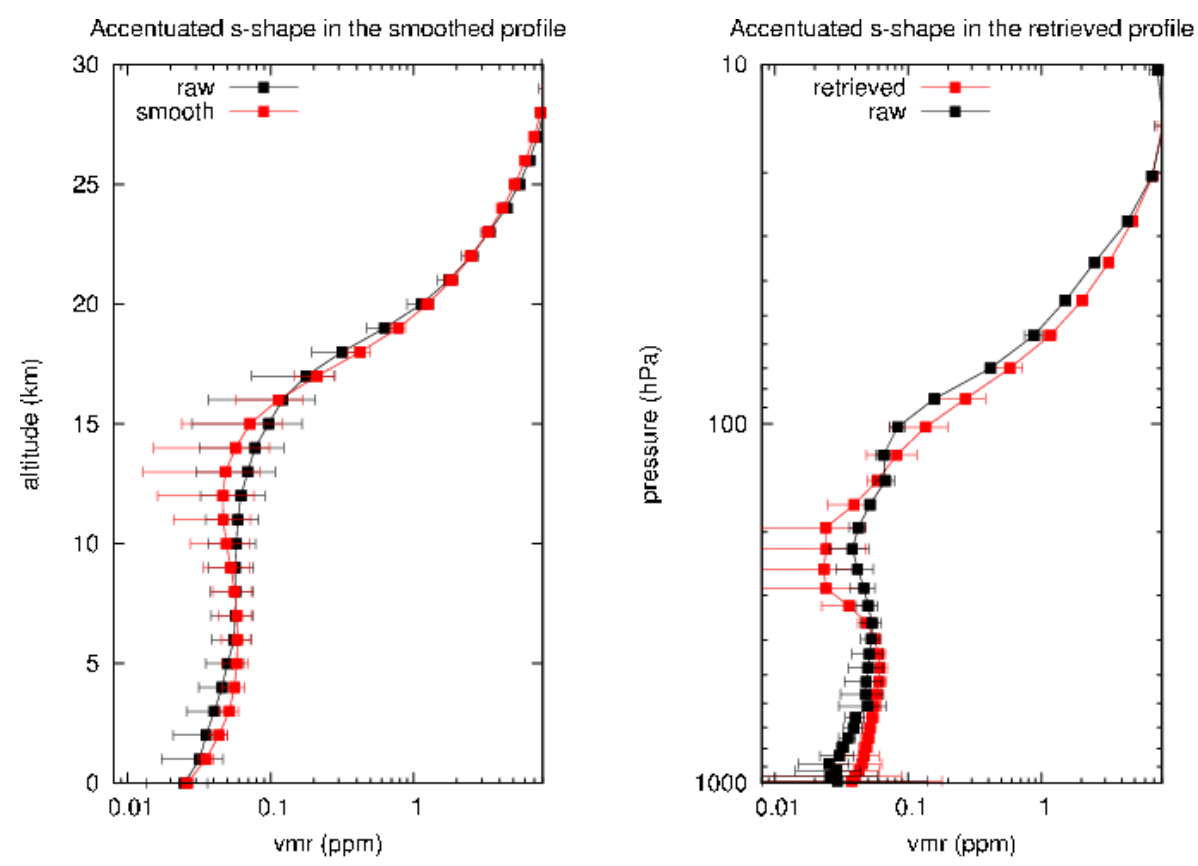

Fig. 13. Effect of the unrealistic accentuation of the "s-shape" of the tropical ozone profile during the smoothing (left panel) and the retrieval (right panel) processes. This effect is visible when comparing the $1 \sigma$ error bars.

product presents low biases for the stratosphere and for the column up to $30 \mathrm{~km}$ (Table 7). In the lower troposphere, the LISA product underestimates ozone amounts and overestimates them in the UTLS region. A good correlation between the ozonesondes and the retrieval is also observed with correlation coefficients close to or larger than 0.8 . The theoretical errors are, on the contrary to the LATMOS/ULB product, underestimated compared to the error estimates prescribed by the rms analysis (Table 7). It is worth noticing that similarly to the midlatitudes, the three products overestimate ozone in the UTLS region.

\section{Conclusions}

In this study, we analyzed the performances of scientific ozone products from IASI produced by three different research groups: LA, LATMOS/ULB, and LISA. The performances were analyzed in terms of retrieval sensitivity and error estimates derived from the retrieval algorithms themselves and in terms of statistical comparisons with independent measurements, the ozonesondes. The main difference in the retrieval methodology between the products is the choice of the constraint matrices and the related a priori. The radiative transfer models are different (lookup tables against lineby-line). However, the used spectroscopic data are similar in the different products. Differences also in the set-up of the retrieval schemes exist between the different products: temperature profiles and surface temperatures can be different as well as the way the emissivity is considered in the retrieval. In a general frame, despite the mentioned differences, the three products display quite similar performances. The error estimates from the lower troposphere to the UTLS region range between 10 and $20 \%$ for all the products. In the stratosphere and for the column integrated up to $30 \mathrm{~km}$ (the maximum height of the sondes), the error estimates are about $5 \%$. The main feature that arises from the comparison with the ozonesondes is an overestimation of the ozone in the UTLS region by the three products in both the midlatitudes and the tropics (bias between 10 and $25 \%$ ).

We have also shown that, although general features are similar, the choice of the method, i.e. the choice of the constraint matrix, different for each product, can influence some characteristics of the products. The sensitivity of the retrieval slightly varies from one product to another. For instance, in the midlatitudes, the LISA product appears slightly more sensitive to the lower troposphere especially in summer. In addition, the biases deduced from the comparison with the ozonesondes are more or less significant depending on the considered atmospheric region. The biases are usually less than $5 \%$ in the midlatitudes except for the LA product in the troposphere (bias of $\sim 11 \%$ ) and for the LATMOS/ULB product in the lower troposphere (bias of $\sim-8 \%$ ). In the tropics, the biases are larger especially in the troposphere for all the products. Moreover, we noticed that the ability of the products to reproduce the natural variability of ozone depends on the strength of the used constraint. The set-up used in the LA retrieval leads to partly 
underestimate the natural variability of ozone while the setup used in the LATMOS/ULB and the LISA retrievals lead to partly overestimate the natural variability of ozone in the winter midlatitudes.

In conclusion, the present validation exercise shows that the three IASI ozone products LA, LATMOS/ULB and LISA, are of sufficiently good quality to be used in geophysical studies. Improvements could be performed to achieve a better representation of the natural variability of ozone such as using specific a priori profiles and constraints depending on the region and the season considered. Explanations were proposed regarding the overestimation of ozone noted in the UTLS region. One of the questions is the potential impact of spectroscopic inconsistencies on the retrievals in this region. Detailed investigations in both the ozone spectroscopy and the retrieval would be necessary to explore this problem. The development of new satellite instruments with improved spectral resolution and radiometric noise would also help to overcome limitations on the vertical resolution and the number of pieces of information accessible in the lowermost troposphere that one can encounter with IASI. The potential successor of IASI on the EPS-SG system, IASI-NG, is one example of future instruments that could help to better describe ozone in the lowermost troposphere and in the UTLS.

Acknowledgements. The authors are grateful to CNRS-INSU for publication support. This study was supported by the French Space Agency CNES (project "IASI-TOSCA"). The IASI mission is a joint mission of Eumetsat and the Centre National d'Etudes Spatiales (CNES, France). The IASI L1 data are distributed in near real time by Eumetsat through the Eumetcast system distribution. The authors acknowledge the Ether French atmospheric database (http://ether.ipsl.jussieu.fr) for providing the IASI L1C and L2 data. The LA group would like to thank M. Matricardi (ECMWF) and R. Saunders (Met. Office) for their support in using the RTTOV algorithm and E. Pavelin (Met. Office) for his help with the 1DVar module. We are also thankfull to P. Brunel (Meteo France) for providing the RTTOV regression coefficients updated with HITRAN2004 and to E. Borbas (U. Wisconsin) for providing the RTTOV UW-IRemis module and the necessary support for its use. P. F. Coheur is Research Associate (Chercheur Qualifié) with F.R.S.-FNRS. The research in Belgium was funded by the F.R.S.-FNRS (M.I.S. nF.4511.08), the Belgian State Federal Office for Scientific, Technical and Cultural Affairs and the European Space Agency (ESA-Prodex arrangements). Financial support by the 'Actions de Recherche Concertées' (Communauté Française de Belgique) is also acknowledged. The LISA group thanks the Institut für Meteorologie und Klimaforschung (IMK), Karlsruhe Institute of Technology (KIT), Germany, for a licence to use the KOPRA radiative transfer model, and especially M. Höpfner for his help to set up the code. Work at LISA was also partly funded by the ESA contract 4000101294/10/NL/CBi. The total ozone columns of OMI were taken from NASA (http://mirador.gsfc.nasa.gov). The ozonesonde data used in this study were provided by the World Ozone and Ultraviolet Data Centre (WOUDC), the Southern Hemisphere Additional Ozonesondes (SHADOZ), and the Global Monitoring Division (GMD) of NOAA's Earth System Research
Laboratory and are publicly available (see http://www.woudc.org, http://croc.gsfc.nasa.gov/shadoz, http://www.esrl.noaa.gov/gmd). The authors thank all those responsible for the WOUDC, SHADOZ, and GMD measurements and archives for making the ozonesonde data available.

Edited by: B. Funke

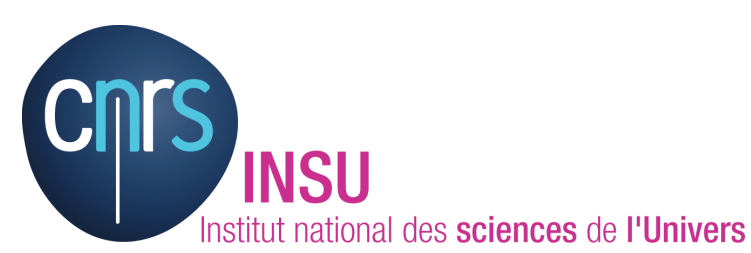

The publication of this article is financed by CNRS-INSU.

\section{References}

Antón, M., Loyola, D., Clerbaux, C., López, M., Vilaplana, J. M., Bañón, M., Hadji-Lazaro, J., Valks, P., Hao, N., Zimmer, W., Coheur, P. F., Hurtmans, D., and Alados-Arboledas, L.: Validation of the Metop-A total ozone data from GOME-2 and IASI using reference ground-based measurements at the Iberian Peninsula, Remote Sens. Environ., 115, 1380-1386, 2011.

Barret, B., Le Flochmoen, E., Sauvage, B., Pavelin, E., Matricardi, M., and Cammas, J. P.: The detection of post-monsoon tropospheric ozone variability over south Asia using IASI data, Atmos. Chem. Phys., 11, 9533-9548, doi:10.5194/acp-11-95332011, 2011.

Borbas, E. E. and Ruston, B. C.: The RTTOV UWiremis IR land surface emissivity module, AS Mission Report NWPSAF-MOVS-042, EUMETSAT Numerical Weather Prediction Satellite Applications Facility, Met Office, Exeter, UK.

Boxe, C. S., Worden, J. R., Bowman, K. W., Kulawik, S. S., Neu, J. L., Ford, W. C., Osterman, G. B., Herman, R. L., Eldering, A., Tarasick, D. W., Thompson, A. M., Doughty, D. C., Hoffmann, M. R., and Oltmans, S. J.: Validation of northern latitude Tropospheric Emission Spectrometer stare ozone profiles with ARC-IONS sondes during ARCTAS: sensitivity, bias and error analysis, Atmos. Chem. Phys., 10, 9901-9914, doi:10.5194/acp10-9901-2010, 2010.

Boynard, A., Clerbaux, C., Coheur, P.-F., Hurtmans, D., Turquety, S., George, M., Hadji-Lazaro, J., Keim, C., and MeyerArnek, J.: Measurements of total and tropospheric ozone from IASI: comparison with correlative satellite, ground-based and ozonesonde observations, Atmos. Chem. Phys., 9, 6255-6271, doi:10.5194/acp-9-6255-2009, 2009.

Clarisse, L., R'Honi, Y., Coheur, P.-F., Hurtmans, D., and Clerbaux, C.: Thermal infrared nadir observations of 24 atmospheric gases, Geophys. Res. Lett., 38, L10802, doi:10.1029/2011GL047271, 2011.

Clerbaux, C., Boynard, A., Clarisse, L., George, M., Hadji-Lazaro, J., Herbin, H., Hurtmans, D., Pommier, M., Razavi, A., Turquety, S., Wespes, C., and Coheur, P.-F.: Monitoring of atmospheric composition using the thermal infrared IASI/MetOp sounder, Atmos. Chem. Phys., 9, 6041-6054, doi:10.5194/acp-9-6041-2009, 2009. 
Coheur, P.-F., Barret, B., Turquety, S., Hurtmans, D., Hadji-Lazaro, J., and Clerbaux, C.: Retrieval and characterization of ozone vertical profiles from a thermal infrared nadir sounder, J. Geophys. Res., 110, D24303, doi:10.1029/2005JD005845, 2005.

Deshler, T., Mercer, J. L., Smit, H. G. J., Stubi, R., Levrat, G., Johnson, B. J., Oltmans, S. J., Kivi, R., Thompson, A. M., Witte, J., Davies, J., Schmidlin, F. J., Brothers, G., and Sasaki, T.: Atmospheric comparison of electrochemical cell ozonesondes from different manufacturers, and with different cathode solution strengths: The Balloon Experiment on Standards for Ozonesondes, J. Geophys. Res., 113, D04307, doi:10.1029/2007JD008975, 2008.

Dufour, G., Eremenko, M., Orphal, J., and Flaud, J.-M.: IASI observations of seasonal and day-to-day variations of tropospheric ozone over three highly populated areas of China: Beijing, Shanghai, and Hong Kong, Atmos. Chem. Phys., 10, 3787-3801, doi:10.5194/acp-10-3787-2010, 2010.

Eremenko, M., Dufour, G., Foret, G., Keim, C., Orphal, J., Beekmann, M., Bergametti, G., and Flaud, J.-M.: Tropospheric ozone distributions over Europe during the heat wave in July 2007 observed from infrared nadir spectra recorded by IASI, Geophys. Res. Lett., 35, L18805, doi:10.1029/2008GL034803, 2008.

Fishman, J., Wozniak, A. E., and Creilson, J. K.: Global distribution of tropospheric ozone from satellite measurements using the empirically corrected tropospheric ozone residual technique: Identification of the regional aspects of air pollution, Atmos. Chem. Phys., 3, 893-907, doi:10.5194/acp-3-893-2003, 2003.

Hurtmans, D., Coheur, P.-F., Wespes, C., Clarisse, L., Scharf, O., Clerbaux, C., Hadji-Lazaro, J., George, M., and Turquety, S.: FORLI radiative transfer and retrieval code for IASI, J. Quant. Spectrosc. Ra., in press, 2012.

Jones, D. B. A., Bowman, K. W., Horowitz, L. W., Thompson, A. M., Tarasick, D. W., and Witte, J. C.: Estimating the summertime tropospheric ozone distribution over North America through assimilation of observations from the Tropospheric Emission Spectrometer, J. Geophys. Res., 113, D18307, doi:10.1029/2007JD009341, 2008.

Keim, C., Eremenko, M., Orphal, J., Dufour, G., Flaud, J.-M., Höpfner, M., Boynard, A., Clerbaux, C., Payan, S., Coheur, P.F., Hurtmans, D., Claude, H., Dier, H., Johnson, B., Kelder, H., Kivi, R., Koide, T., López Bartolomé, M., Lambkin, K., Moore, D., Schmidlin, F. J., and Stübi, R.: Tropospheric ozone from IASI: comparison of different inversion algorithms and validation with ozone sondes in the northern middle latitudes, Atmos. Chem. Phys., 9, 9329-9347, doi:10.5194/acp-9-9329-2009, 2009.

Komhyr, W. D. , Barnes, R. A., Brothers, G. B., Lathrop, J. A., and Opperman, D. P.: Electrochemical concentration cell ozonesonde performance evaluation during STOIC 1989, J. Geophys. Res., 100, 9231-9244, doi:10.1029/94JD02175, 1995.

Kulawik, S. S., Osterman, G., Jones, D. B. A., and Bowman, K. W.: Calculation of altitude-dependent Tikhonov constraints for TES nadir retrievals, IEEE T. Geosci. Remote, 44, 1334-1342, 2006.

Liu, X., Chance, K. V., Sioris, C. E., Spurr, R. J. D., Kurosu, T. P., Martin, R. V., and Newchurch, M. J.: Ozone profile and tropospheric ozone retrievals from Global Ozone Monitoring Experiment: Algorithm description and validation, J. Geophys. Res., 110, D20307, doi:10.1029/2005JD006240, 2005.
Matricardi, M.: Technical Note: An assessment of the accuracy of the RTTOV fast radiative transfer model using IASI data, Atmos. Chem. Phys., 9, 6899-6913, doi:10.5194/acp-9-6899-2009, 2009.

Matricardi, M., Chevallier, F., Kelly, G., and Thepaut, J. N.: An improved general fast radiative transfer model for the assimilation of radiance observations, Q. J. Roy. Meteorol. Soc., 130, 153173, 2004.

McPeters, R. D., Labow, G. J., and Logan, J. A.: Ozone climatological profiles for satellite retrieval algorithms, J. Geophys. Res., 112, D05308, doi:10.1029/2005JD006823, 2007.

Nassar, R., Logan, J. A., Worden, H. M., Megretskaia, I. A., Bowman, K. W., Osterman, G. B., Thompson, A. M., Tarasick, D. W., Austin, S., Claude, H., Dubey, M. K., Hocking, W. K., Johnson, B. J., Joseph, E., Merrill, J., Morris, G. A., Newchurch, M., Oltmans, S. J., Posny, F., Schmidlin, F. J., Vömel, H., Whiteman, D. N., and Witte, J. C.: Validation of Tropospheric Emission Spectrometer (TES) Nadir ozone profiles using ozonesonde measurements, J. Geosphys. Res., 113, D15S17, doi:10.1029/2007JD008819, 2008.

Pavelin, E. G., English, S. J., and Eyre, J. R.: The assimilation of cloud-affected infrared satellite radiances for numerical weather prediction, Q. J. Roy. Meteorol. Soc., 134, 737-749, 2008.

Rodgers, C. D.: Inverse methods for atmospheric sounding: Theory and practice, vol. 2, World Scientific Publications, Series on Atmospheric, Ocean, Planet. Phys., Singapore, 2000.

Rodgers, C. D. and Connor, B. J.: Intercomparison of remote sounding instruments, J. Geosphys. Res., 108, 4116, doi:10.1029/2002JD002299, 2003.

Rothman, L. S., Jacquemart, D., Barbe, A., Chris Benner, D., Birk, M., Brown, L. R., Carleer, M. R., Chackerian Jr., C., Chance, K., Coudert, L. H., Dana, V., Devi, V. M., Flaud, J.-M., Gamache, R. R., Goldman, A., Hartmann, J.-M., Jucks, K. W., Maki, A. G., Mandin, J.-Y., Massie, S. T., Orphal, J., Perrin, A., Rinsland, C. P., Smith, M. A. H., Tennyson, J., Tolchenov, R. N., Toth, R. A., Vander Auwera, J., Varanasi, P., and Wagner, G.: The HITRAN 2004 molecular spectroscopic database, J. Quant. Spectrosc. Ra., 96, 139-204, 2005.

Saunders, R., Matricardi, M., and Brunel, P., An improved fast radiative transfer model for assimilation of satellite radiance observations, Q. J. Roy. Meteorol. Soc., 125, 1407-1425, 1999.

Scannell, C., Hurtmans, D., Boynard, A., Hadji-Lazaro, J., George, M., Delcloo, A., Tuinder, O., Coheur, P.-F., and Clerbaux, C.: Antarctic ozone hole as observed by IASI/MetOp for 2008-2010, Atmos. Meas. Tech., 5, 123-139, doi:10.5194/amt-5-123-2012, 2012.

Schlüssel, P., Hultberg, T. H., Phillips, P. L., August, T., and Calbet, X.: The operational IASI Level 2 processor. Advances in Space Research, COSPAR 2005, 36, 982-988, doi:10.1016/j.asr.2005.03.008, 2005.

Schneider, M., Redondas, A., Hase, F., Guirado, C., Blumenstock, T., and Cuevas, E.: Comparison of ground-based Brewer and FTIR total column $\mathrm{O}_{3}$ monitoring techniques, Atmos. Chem. Phys., 8, 5535-5550, doi:10.5194/acp-8-5535-2008, 2008.

Seinfeld, J. H. and Pandis, S. N.: Atmospheric Chemistry and Physics, from Air Pollution to Climate Change, John Wiley \& Sons Inc., Toronto, Canada, 1997. 
Smit, H. G. J., Straeter, W., Johnson, B., Oltmans, S., Davies, J., Tarasick, D. W., Hoegger, B., Stubi, R., Schmidlin, F., Northam, T., Thompson, A., Witte, J., Boyd, I., and Posny, F.: Assessment of the performance of ECC-ozonesondes under quasi-flight conditions in the environmental simulation chamber: Insights from the Juelich Ozone Sonde Intercomparison Experiement (JOSIE), J. Geophys. Res., 112, D19306, doi:10.1029/2006JD007308, 2007.

Steck, T.: Methods for determining regularization for atmospheric retrieval problems, Appl. Optics, 41, 1788-1797, 2002.

Stiller, G. P. (Ed.) with contributions from v. Clarmann, T., Dudhia, A., Echle, G., Funke, B., Glatthor, N., Hase, F., Höpfner, M., Kellmann, S., Kemnitzer, H., Kuntz, M., Linden, A., Linder, M., Stiller, G. P., and Zorn, S.: The Karlsruhe Optimized and Precise Radiative Transfer Algorithm (KOPRA), vol. FZKA 6487 of Wissenschaftliche Berichte, Forschungszentrum Karlsruhe, Germany, 2000 .

Thompson, A. M., Witte, J. C., McPeters, R. D., Oltmans, S. J., Schmidlin, F. J., Logan, J. A., Fujiwara, M., Kirchhoff, V. W. J. H., Posny, F., Coetzee, G. J. R., Hoegger, B., Kawakami, S., Ogawa, T., Johnson, B. J., Vömel, H., and Labow, G.: Southern Hemisphere Additional Ozonesondes (SHADOZ) 1998-2000 tropical ozone climatology 1. Comparison with Total Ozone Mapping Spectrometer (TOMS) and ground-based measurements, J. Geophys. Res., 108, 8238, doi:10.1029/2001JD000967, 2003.

Thouret, V., Marenco, A., Logan, J. A., Nédélec, P., and Grouhel, C.: Comparisons of ozone measurements from the MOZAIC airborne program and the ozone sounding network at eight locations, J. Geophys. Res., 103, 25695-25720, 1998.

Tikhonov, A.: On the Solution of Incorrectly Stated Problems and a Method of Regularisation, Dokl. Acad. Nauk SSSR, 151, 501504, 1963.
Turquety, S., Hadji-Lazaro, J., and Clerbaux, C.: First satellite ozone distributions retrieved from nadir highresolution infrared spectra, Geophys. Res. Lett., 29, 2198, doi:10.1029/2002GL016431, 2002.

Turquety, S., Hurtmans, D., Hadji-Lazaro, J., Coheur, P.-F., Clerbaux, C., Josset, D., and Tsamalis, C.: Tracking the emission and transport of pollution from wildfires using the IASI CO retrievals: analysis of the summer 2007 Greek fires, Atmos. Chem. Phys., 9, 4897-4913, doi:10.5194/acp-9-4897-2009, 2009.

Viatte, C., Schneider, M., Redondas, A., Hase, F., Eremenko, M., Chelin, P., Flaud, J.-M., Blumenstock, T., and Orphal, J.: Comparison of ground-based FTIR and Brewer $\mathrm{O}_{3}$ total column with data from two different IASI algorithms and from OMI and GOME-2 satellite instruments, Atmos. Meas. Tech., 4, 535-546, doi:10.5194/amt-4-535-2011, 2011.

Wan, Z.: New refinements and validation of the MODIS landsurface temperature/emissivity products. Remote Sensing of Environment, Remote Sens. Environ., 112, 59-74, 2008.

Worden, H. M., Logan, J. A., Worden, J. R., Beer, R., Bowman, K., Clough, S. A., Eldering, A., Fisher, B. M., Gunson, M. R., Herman, R. L., Kulawik, S. S., Lampel, M. C., Luo, M., Megretskaia, I. A., Osterman, G. B., and Shephard, M. W.: Comparisons of Tropospheric Emission Spectrometer (TES) ozone profiles to ozonesondes: Methods and initial results, J. Geophys. Res., 112, D03309, doi:10.1029/2006JD007258, 2007.

Worden, H. M., Bowman, K. W., Eldering, A., and Beer, R.: Satellite measurements of the clear-sky greenhouse effect from tropospheric ozone, Nat. Geosci., 1, 305-308, doi:10.1038/ngeo182, 2008.

Zhou, D. K., Larar, A. M., Liu, X., Smith, W. L., Strow, L. L., Yang, P., Schlu"ssel, P., and Calbet, X.: Global land surface emissivity retrieved from satellite ultraspectral IR measurements, IEEE T. Geosci. Remote, 49, 1277-1290, doi:10.1109/TGRS.2010.2051036, 2011. 